\title{
Instalaciones del Pabellón de España en la Expo 2008
}

\section{Installations in the Spanish Pavilion for the Expo 2008}

\author{
$\underline{\text { C. Martín Gómez }}^{(*)}$, P. López ${ }^{(* *)}$, A. Fiestas ${ }^{(* *)}$
}

\section{RESUMEN}

El objeto de este artículo es describir las instalaciones técnicas del Pabellón de España para la Exposición Internacional de Zaragoza 2008 'Agua y desarrollo sostenible'. Esta descripción implica narrar el proceso proyectual seguido hasta alcanzar un edificio de bajo consumo energético, no sólo por los materiales y sistemas constructivos empleados, sino también por la eficiencia energética de las instalaciones planteadas. Por ello, se estudia desde la implantación global de los espacios requeridos por las instalaciones hasta sus principales características, de manera que el lector comprenda el funcionamiento de las mismas en relación con el conjunto e individualmente.

Como se comprueba a lo largo del artículo, se trata de una obra arquitectónica que integra las medidas pasivas de ahorro energético con la innovación tecnológica de las instalaciones, consiguiendo de esta manera un icono ejemplarizante -dada la repercusión mediática de un evento como una exposición internacional- para la arquitectura sostenible (que no 'arquitectura bioclimática').

\section{$149-47$}

Palabras clave: arquitectura, instalaciones, eficiencia energética, acondicionamiento higrotérmico, integración tecnológica.
Informes de la Construcción Vol. 61, 515, 5-22, julio-septiembre 2009 ISSN: 0020-0883 elSSN: 1988-3234 doi: $10.3989 / \mathrm{ic} .08 .018$

\section{SUMMARY}

Is the subject of this article describing the technical installations in the Spanish Pavilion for the International Exhibition "Water and sustainable development" in Saragossa 2008. This description follows the design process until it achieves a low energy consumption building, not only on account of the materials and constructive systems employed, but also on account of the energy efficiency of the installations proposed. For this reason, it is studied from the global siting of the spaces required for installations, to the principal installations, so that the reader can understand the individual functioning of the each, independently and in its relationship to the whole.

As one can confirm throughout the article, we are dealing with a work of architecture that optimally integrates passive energy savings with innovative installations technologies, achieving an exemplary icon-given the media importance of an event like an international exhibition-for sustainable architecture (rather than 'bioclimatic' architecture).

Keywords: architecture, installations, energy efficiency, HVAC, technological integration.

(*Dr. Arquitecto. Responsable de la Dirección de Obra de las instalaciones del Pabellón de España. Coordinador del Grupo de Investigación de Integración de Instalaciones y Energía en Arquitectura y Urbanismo de la Escuela Técnica Superior de Arquitectura de la Universidad de Navarra (España).

${ }^{(* *}$ Ingeniero Técnico Industrial. Responsable de las instalaciones de la empresa constructora del Pabellón de España.

${ }^{(* *)}$ Arquitecta. Ex alumna becada del Departamento de Instalaciones de la Escuela Técnica Superior de Arquitectura de la Universidad de Navarra (España) durante el curso 2007-2008. 
1. Vistas generales del edificio (Fot. Pedro Pegenaute).

2. Lámina de agua perimetral (Fot. Pedro Pegenaute).
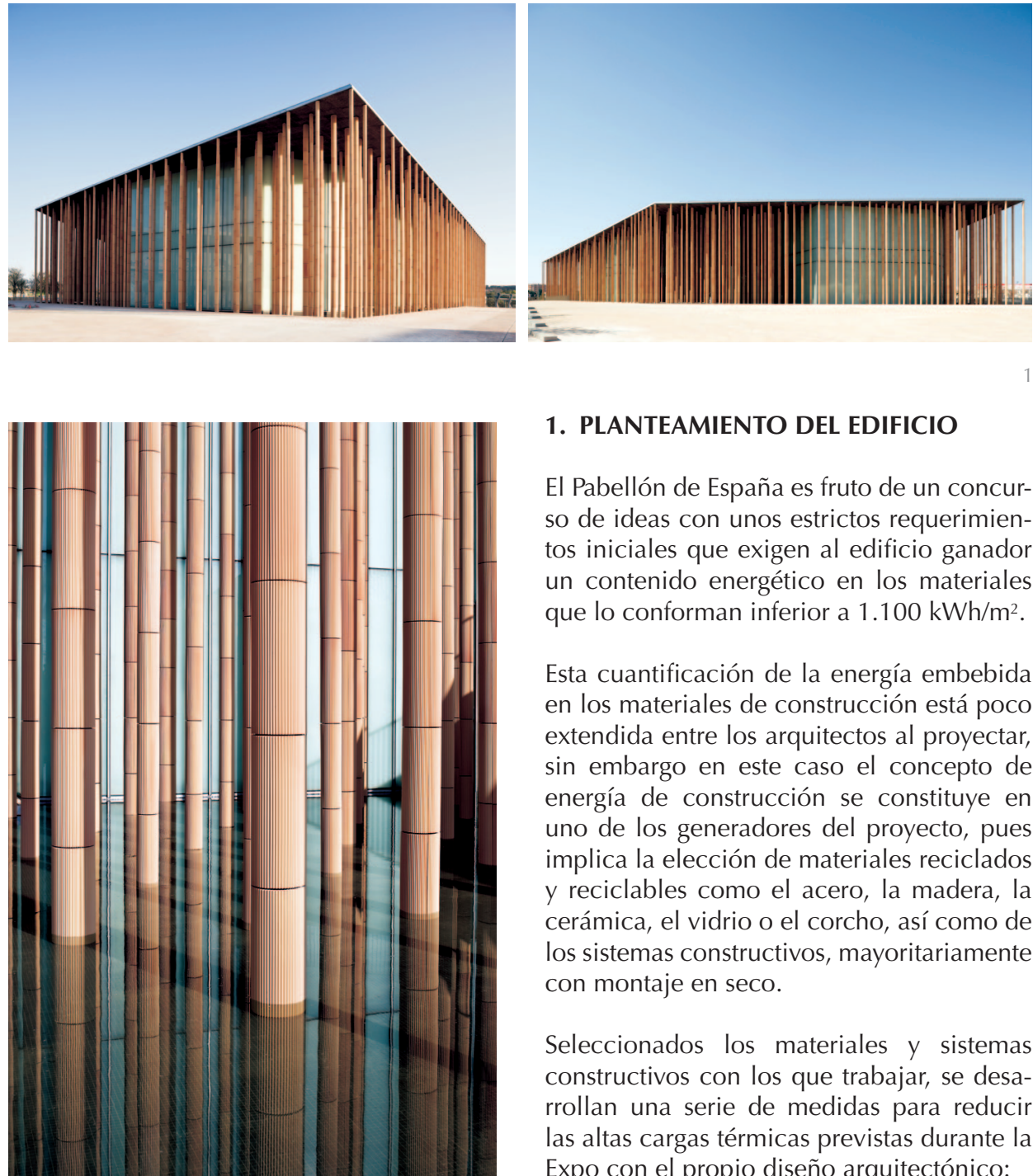

\section{PLANTEAMIENTO DEL EDIFICIO}

El Pabellón de España es fruto de un concurso de ideas con unos estrictos requerimientos iniciales que exigen al edificio ganador un contenido energético en los materiales que lo conforman inferior a $1.100 \mathrm{kWh} / \mathrm{m}^{2}$.

Esta cuantificación de la energía embebida en los materiales de construcción está poco extendida entre los arquitectos al proyectar, sin embargo en este caso el concepto de energía de construcción se constituye en uno de los generadores del proyecto, pues implica la elección de materiales reciclados y reciclables como el acero, la madera, la cerámica, el vidrio o el corcho, así como de los sistemas constructivos, mayoritariamente con montaje en seco.

Seleccionados los materiales y sistemas constructivos con los que trabajar, se desarrollan una serie de medidas para reducir las altas cargas térmicas previstas durante la Expo con el propio diseño arquitectónico:

- Una gran cubierta proporciona sombreamiento al Pabellón y al área circundante exterior, reduciendo de este modo la transmisión de calor en verano a los espacios interiores procedente de la radiación solar directa.

- La densidad de pilares se aumenta en la fachada oeste, para evitar la no deseada radiación solar directa desde esta orientación en verano.

- La lámina de agua perimetral proporciona una importante reducción de las oscilaciones térmicas alrededor de los espacios principales del Pabellón. ciales de baja energía de construcción y de mantenimiento del concurso, se han mantenido en las fases de redacción del proyecto de ejecución, durante la propia ejecución y la puesta en marcha del Pabellón. Esto es, evidenciar cómo las propuestas del Pabellón de España no se han quedado en la mera investigación teórica o en la fase de concurso, sino que se ha seguido un proyecto coherente de implantación de medidas de ahorro energético en las instalaciones hasta su utilización por parte de los usuarios del Pabellón.
En lo que se refiere a la organización interior del Pabellón, la planta baja y parte del semisótano se dedican a las zonas de exposiciones públicas; el resto del semisótano se habilita para salas técnicas, locales auxiliares y el aparcamiento. En la planta primera se ubican locales de acceso restringido como las oficinas, una sala de uso polivalente, la cocina y el restaurante. Se reserva la cubierta como espacio para albergar el resto de las instalaciones ${ }^{1}$.
"Pabellón de España", Editor Arquitectura Viva, 2007. ISBN 978-84-612-4460-7. 
Previamente al desarrollo de las instalaciones se han calculado las cargas térmicas del edificio para las $8.760 \mathrm{~h}$ del año. Este cálculo lo desarrolló la Fundación CENERCIEMAT con el software de simulación 'TRNSYS' (Solar Energy Laboratory, University of Wisconsin and Transsolar Stuttgart), y utilizando como datos climáticos de la ciudad de Zaragoza tanto los procedentes del Instituto Nacional de Meteorología, como los publicados por el U.S. Departament of Energy para el programa 'Energy plus'.

Las características de los cerramientos utilizadas en el cálculo son las siguientes:

- Vidrio de cerramiento (Saint Gobain CLIMAPLUS FUTUR AR 1.1 4/15/4): $U=1,1$

$\mathrm{W} / \mathrm{m}^{2} \mathrm{~K}$ Factor solar $=0,609$

- Cubierta: $U=0,321 \mathrm{~W} / \mathrm{m}^{2} \mathrm{~K}$

- Forjado entre plantas: $\mathrm{U}=0,682 \mathrm{~W} / \mathrm{m}^{2} \mathrm{~K}$

- Forjado en contacto con el terreno: $U=$ $0,41 \mathrm{~W} / \mathrm{m}^{2} \mathrm{~K}$

- Muro en contacto con el terreno: $U=$ $0,675 \mathrm{~W} / \mathrm{m}^{2} \mathrm{~K}$

Las renovaciones de aire interior (incluidas las infiltraciones) se estimaron de acuerdo con el "Standard ASHRAE 62-1999 Ventilation for Aceptable Indoor Air Quality", que fija la ventilación mínima en $8 \mathrm{l} / \mathrm{s}$ por persona para teatros/auditorios. También se han considerado los flujos de aire entre las zonas situadas en una misma planta, con una velocidad del aire de $0,18 \mathrm{~m} / \mathrm{s}$.

Para realizar el cálculo de cargas térmicas, el Pabellón se dividió en nueve zonas (tres en cada una de las plantas): cada planta consta de una zona norte, zona sur-oeste y zona sur-este. Para cada una de estas nueve zonas se plantea una distribución de cargas
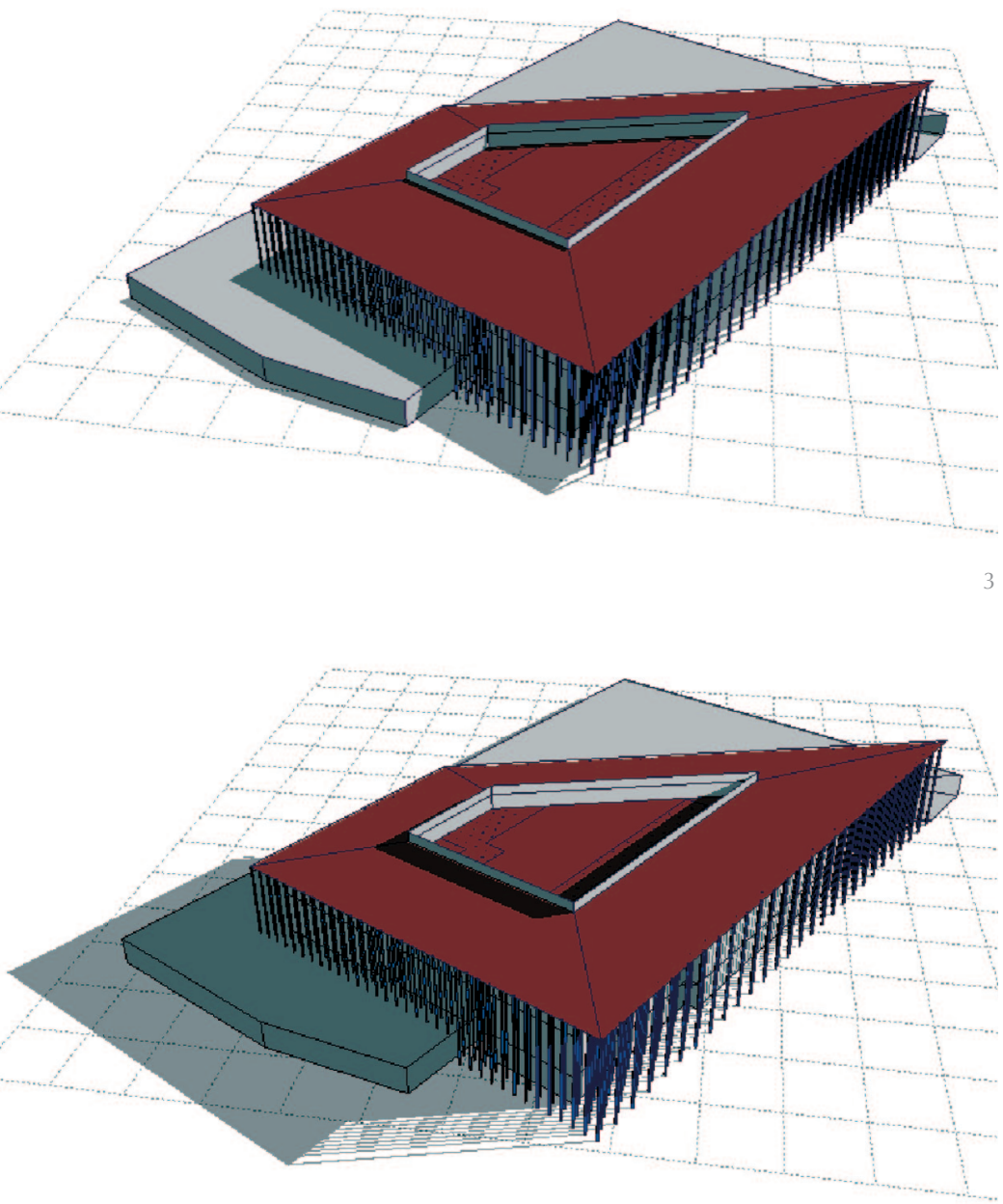

internas (personas y equipos) acorde con la información disponible en el momento del cálculo². El resumen de las cargas térmicas totales puede observarse en la gráfica que acompaña estas líneas (pág. siguiente). realizado durante la redacción del

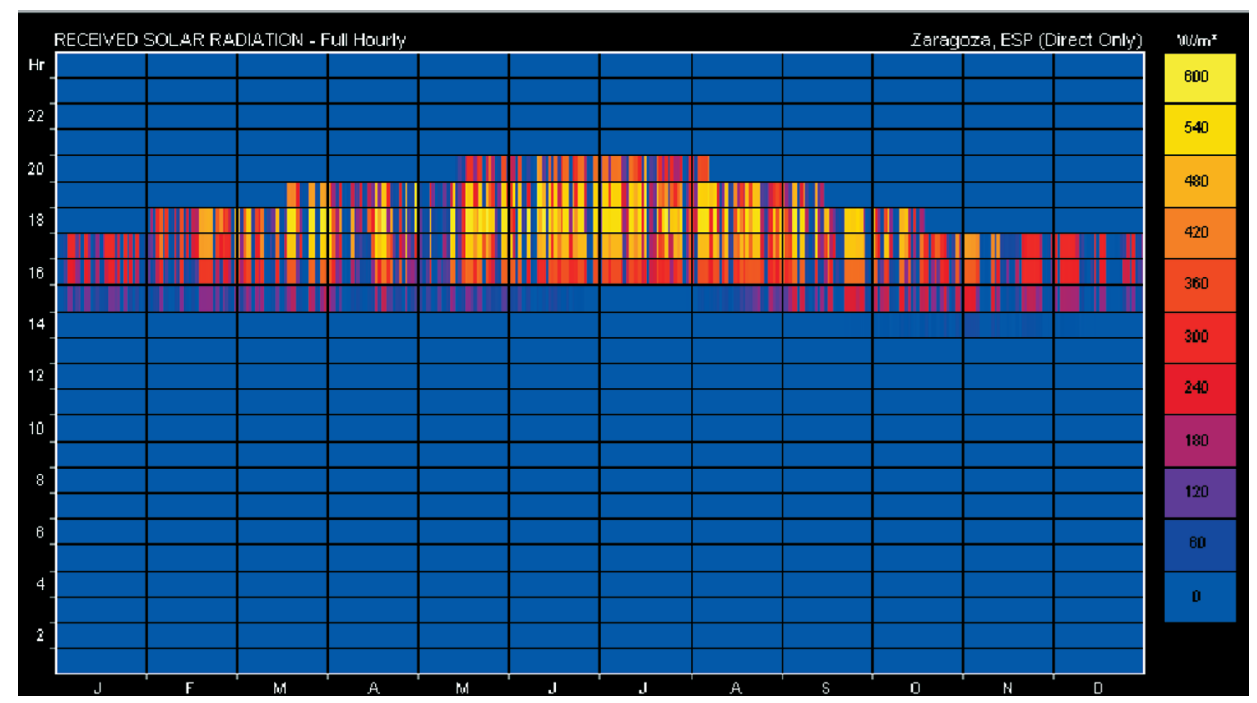

3. Ejemplo del análisis de sombras proyecto de ejecución. 21 Junio, 12:00 h (Fuente: Fundación CENERCIEMAT). El análisis de soleamiento se realiza para cada hora solar a lo largo del año.

4. Análisis de sombras. 21 Diciembre, 12:00 h (Fuente: Fundación CENERCIEMAT)

5. En la elaboración del proyecto también se ha obtenido la irradiancia de los diferentes cerramientos. La gráfica aquí reproducida muestra la irradiancia de un cerramiento situado en la planta baja (Fuente: Fundación CENER-CIEMAT). 

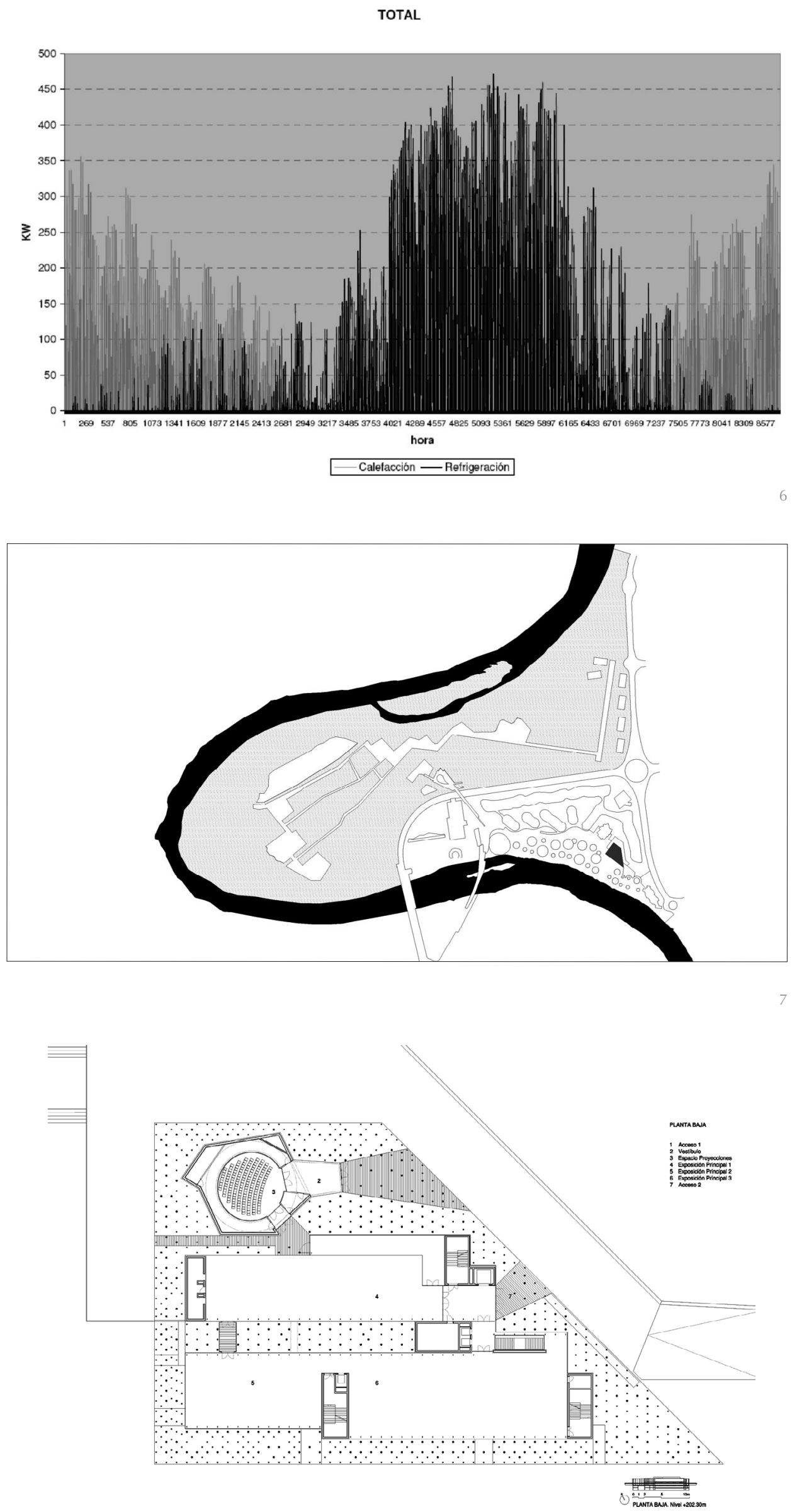


\section{CRITERIOS DE DISEÑO DE LAS INSTALACIONES}

Tras haber reducido la demanda energética del Pabellón con la propia arquitectura y realizado el cálculo de cargas, se diseña el sistema de instalaciones (el consumidor de la energía de mantenimiento) para que trabaje con un alto grado de eficiencia y lograr un bajo consumo final. Este punto se cuida especialmente ya que el consumo de energía que supone mantener los ambientes interiores en unas condiciones adecuadas, es el gasto energético más importante de los edificios, y se produce a lo largo de toda su vida útil3. Dos conceptos son los que guían la implantación de este sistema de instalaciones: el contenedor de instalaciones de la cubierta y la 'membrana energética' de los forjados. Así, la mayor parte de las instalaciones se agrupan en la cubierta, facilitando considerablemente la gestión y mantenimiento de las mismas. Existen otros locales técnicos de superficie menor en el semisótano; son los locales que albergan los imprescindibles suministros energéticos (agua potable, red de incendios procedente de la Expo, electricidad, e intercambiadores de calor) que quedan comunicados con las instalaciones de la cubierta por un volumen técnico vertical.

Desde este espacio vertical, ubicado en el baricentro energético del Pabellón, se distribuyen horizontalmente las instalaciones a través de un forjado técnico desde el que se alimenta tanto la planta superior (en forma de suelo técnico) como la inferior (desde la superficie comprendida entre las vigas de madera). Esta 'membrana energética', tal y como se denominó durante el proyecto, conforma un volumen horizontal tecnológico para albergar todas las instalaciones del Pabellón, y que mostró sus ventajas de mantenimiento durante los meses de funcionamiento de la Expo. Este diseño requirió de una compleja y ordenada puesta en obra, pues en el mismo espacio trabajaban de manera casi simultánea los distintos gremios; así, aunque en un primer momento estaba previsto que cada instalación tuviera su soporte propio, esta cuestión se rediseñó con la realización de soportes comunes a varias instalaciones, de modo que se taladrase lo menos posible los tableros de madera que sirven de base. El orden de montaje de esta 'membrana energética' fue el siguiente:

- Vigas de madera.

- Panel inferior de madera reciclada.

- Replanteo de los soportes del panel superior y de los trazados principales de las redes de instalaciones.

- Tuberías de la red de incendios.
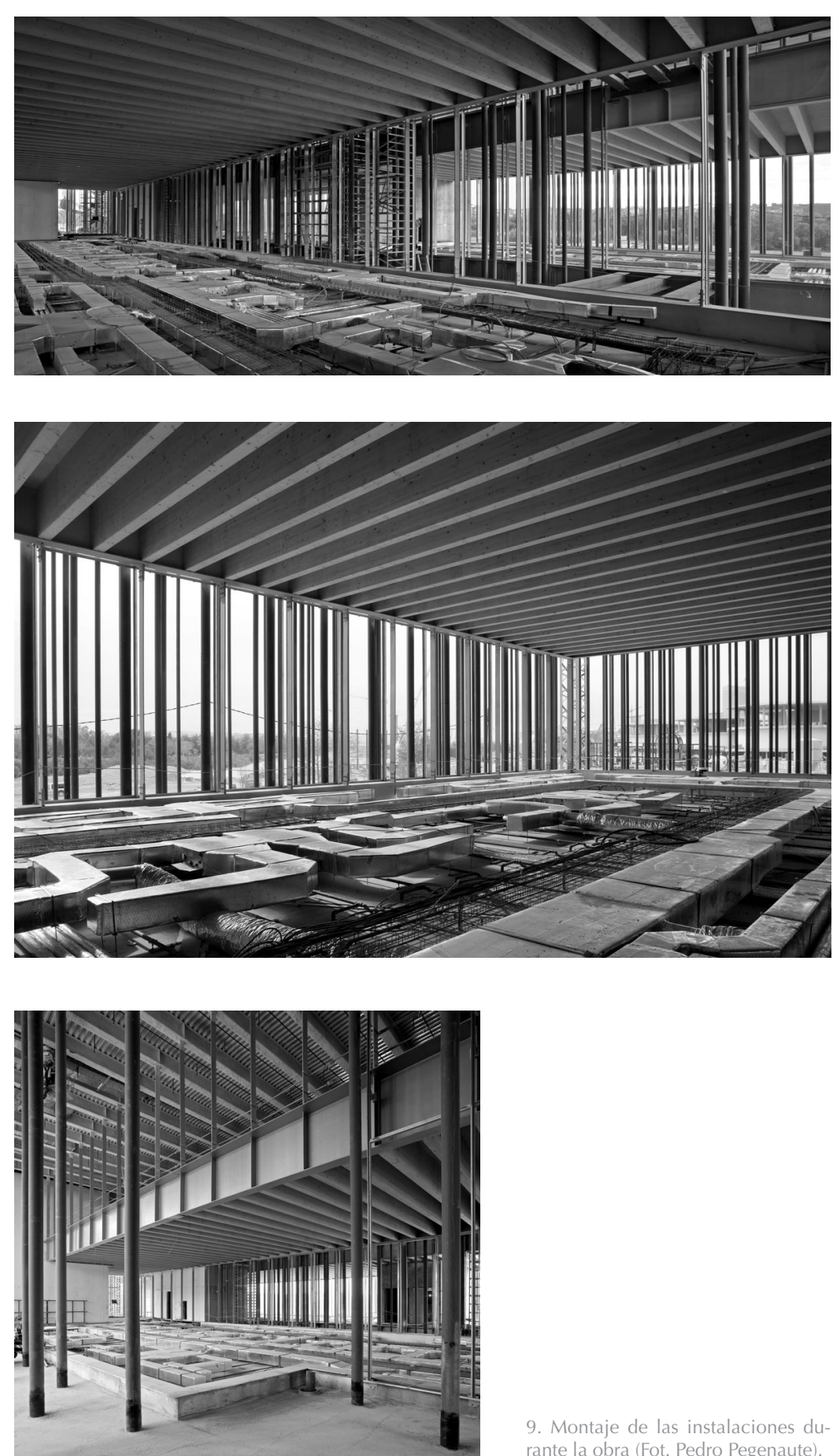

9. Montaje de las instalaciones durante la obra (Fot. Pedro Pegenaute).

- Tuberías de las redes de fontanería, de recogida de condensados y de climatización.

- Conductos de aire acondicionado y fancoils.

- Bandejas de las redes de electricidad y de datos.

- Tendido de cableado y conexión de los equipos.

- Colocación del panel superior de madera reciclada, de las cajas de registro eléctricas y de datos en el suelo, así como de las rejillas de aire acondicionado.

- Colocación del suelo de acabado.
${ }^{3}$ Cfr. Martín Gómez, César. "Las instalaciones. Investigación Energética", Editor Arquitectura Viva, 2007, pp. 70-75. 


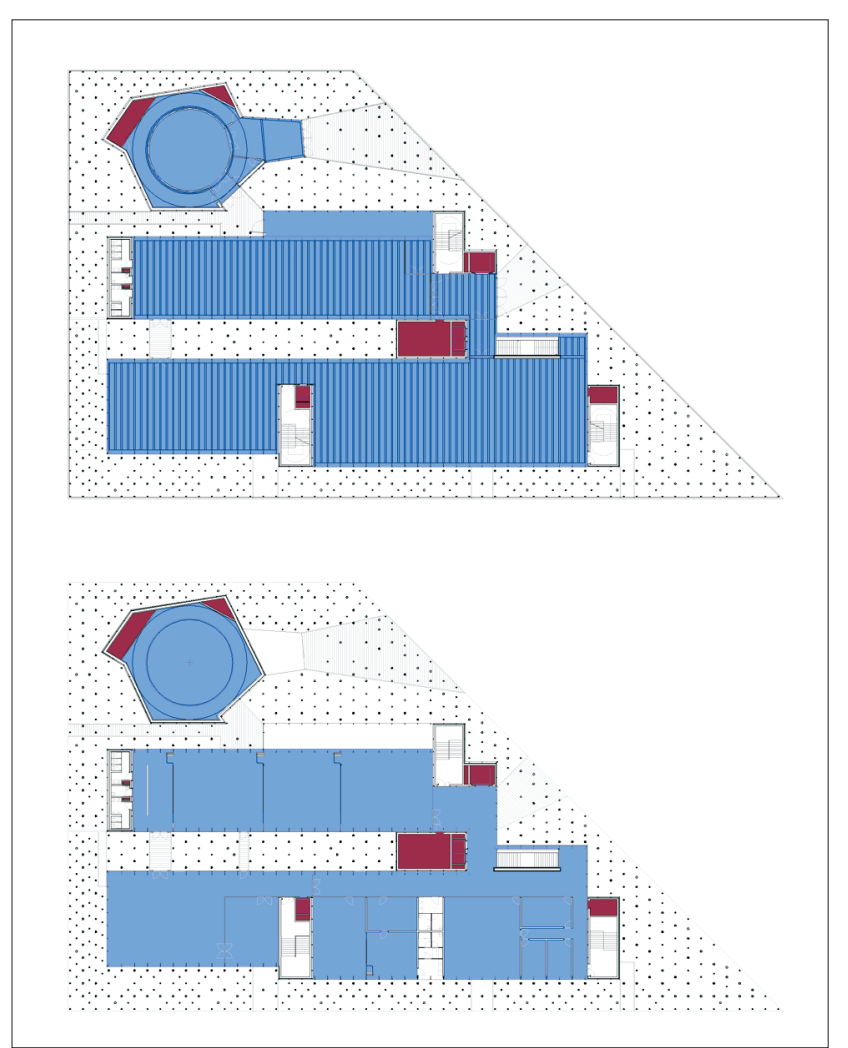

Espacio ocupado por instalaciones
SEYENDA
SEGCes for installations Salas con alre acondicionado
rooms whth air condfitioning

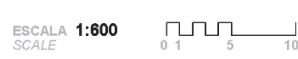
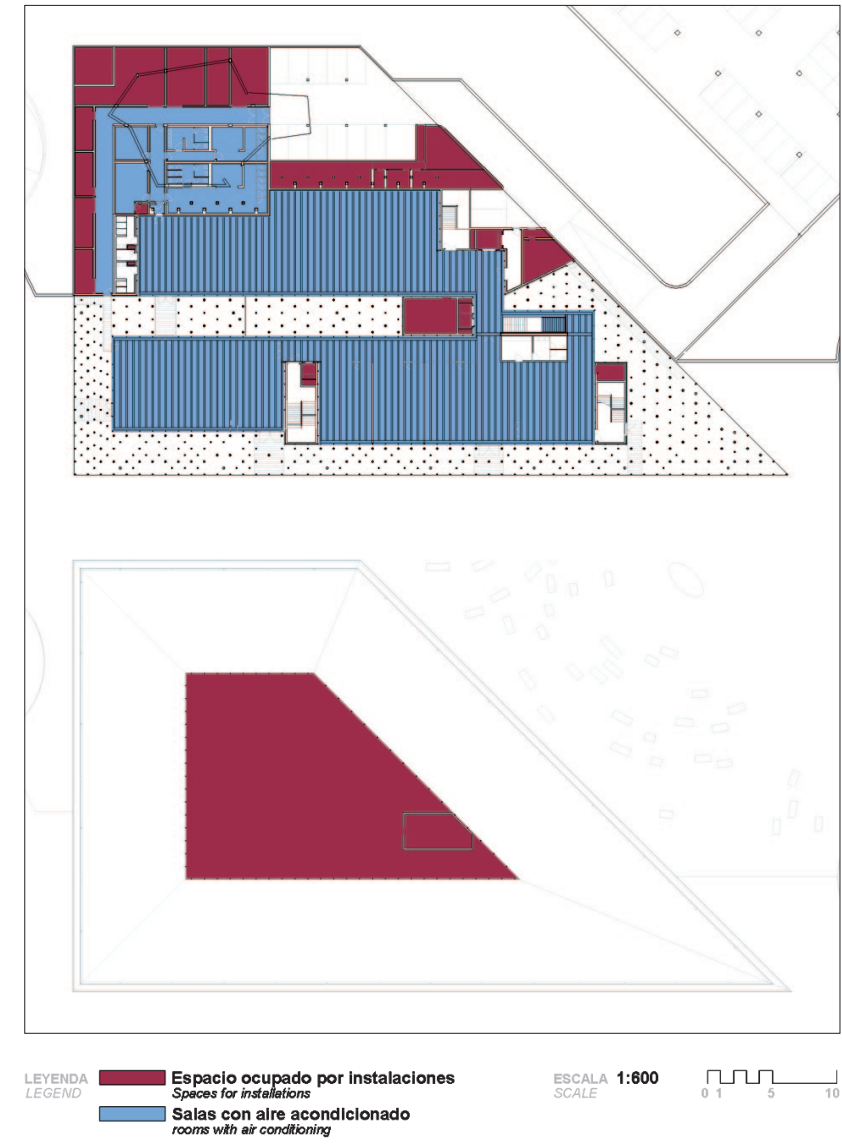

ESCALA 1:600
10. Zonas acondicionadas y espacios requeridos para las instalaciones. La ubicación de los paneles fotovoltaicos coincide en su totalidad con el espacio técnico de la cubierta, de tal modo que los paneles fotovoltaicos logran proporcionan protección a las máquinas que se ubican debajo.

4 El sistema colocado está formado por los siguientes elementos: Recipiente de 11,36 I de agente extintor (tipo 'Ansulex') con cartucho propelente de nitrógeno; boquillas de distribución del agente extintor situadas en la campana y en un tramo de 1,50 m del conducto de evacuación de humos; detectores térmicos, tipo fusibles, que provocan el disparo automático del agente extintor; sistema de tuberías de acero inoxidable.
A continuación, en los siguientes apartados, se comentan las principales particularidades de cada instalación en comparación a proyectos de similares características.

\section{SECTORIZACIÓN Y PROTECCIÓN CONTRA INCENDIOS}

Todas las zonas de las tres plantas del edificio dedicadas a exposiciones y actividades complementarias forman un único sector de incendios, con una superficie de $4.772 \mathrm{~m}^{2}$, protegido por una instalación de rociadores automáticos de agua. Además del sector principal, son sectores de incendio los siguientes espacios:

- Aparcamiento de vehículos.

- Centro de transformación.

- Sala de cuadros generales de baja tensión.

- Vestuarios, aseos y locales anexos.

- Salas técnicas que no constituyen locales de riesgo.

- Local dedicado a la proyección de cine.

Las medidas activas de protección contra incendios incluyen la colocación de extintores, bocas de incendios equipadas y extinción por $\mathrm{CO}_{2}$ en el cuadro eléctrico principal.
La extinción de la campana de la cocina (eléctrica) de planta primera -visible desde la zona de restauración por el público- se realiza con un agente extintor de uso específico para los fuegos que se previsiblemente se pueden producir en cocinas. Curiosamente, este sistema procede de la tecnología de protección contra fuegos utilizada en las cocinas de los submarinos militares ${ }^{4}$.

\section{SANEAMIENTO Y FONTANERÍA}

Las aguas pluviales se conducen a través de bajantes situadas en el interior de pilares metálicos no estructurales, aprovechando el alma hueca de los mismos, a los depósitos de compensación que dan suministro a los estanques del Pabellón. Este almacenamiento de las aguas pluviales tiene por objeto complementar el abastecimiento de la red de riego que suministra agua a los estanques. Para la regulación y depuración del agua de los estanques se realizan dos instalaciones (una por cada nivel) con los siguientes componentes:

- Depósitos de regulación:

o Para el estanque del nivel 202,20 m su capacidad es de $50 \mathrm{~m}^{3}$. 
o Para el estanque de 198,05 m, su capacidad total es de $112,5 \mathrm{~m}^{3}$, de la cual $62,5 \mathrm{~m}^{3}$ se dedican a reserva de agua de Iluvia. Cuando el nivel de dicho depósito sobrepasa a una determinada cota el agua se vierte desde aquel hacia la red de recogida de aguas pluviales.

- Bombeo desde los depósitos a los estanques. Se instalan las siguientes bombas:

o Para el estanque de nivel 202,20 m: dos bombas horizontales de $35,2 \mathrm{~m}^{3} / \mathrm{h}$ de caudal y 196,2 kPa, con motor de $4 \mathrm{~kW}$. o Para el estanque de nivel 198,05 m: dos bombas sumergidas de $35,2 \mathrm{~m}^{3} / \mathrm{h}$ de caudal y 196,2 kPa, con motor de 6,5 kW. o Se instala también una bomba horizontal de $10,5 \mathrm{~m}^{3} / \mathrm{h}$ de caudal y $372,8 \mathrm{kPa}$, con motor de $3 \mathrm{~kW}$, para el lavado de filtros.

Respecto a la red de fontanería, se utilizan griferías con aireadores para reducir el consumo de agua, y sistemas de doble descarga para los inodoros.

En la Expo del Agua, se constituye en un objetivo de partida concienciar a los visitantes sobre el consumo de este recurso por lo que, en una pantalla situada junto a la tienda del Pabellón, se expone a los visitantes el consumo instantáneo e histórico de agua, a través de un sistema de monitorización conectado a la señal de datos que proporciona el contador de agua del Pabellón.

\section{ELECTRICIDAD}

El suministro de electricidad al Pabellón se realiza en media tensión, por lo que ha sido necesario instalar un centro de trans-

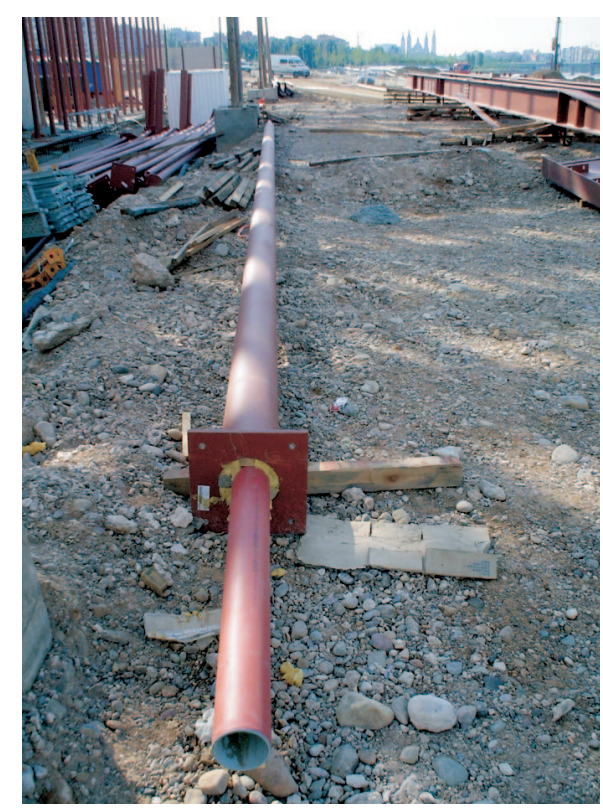

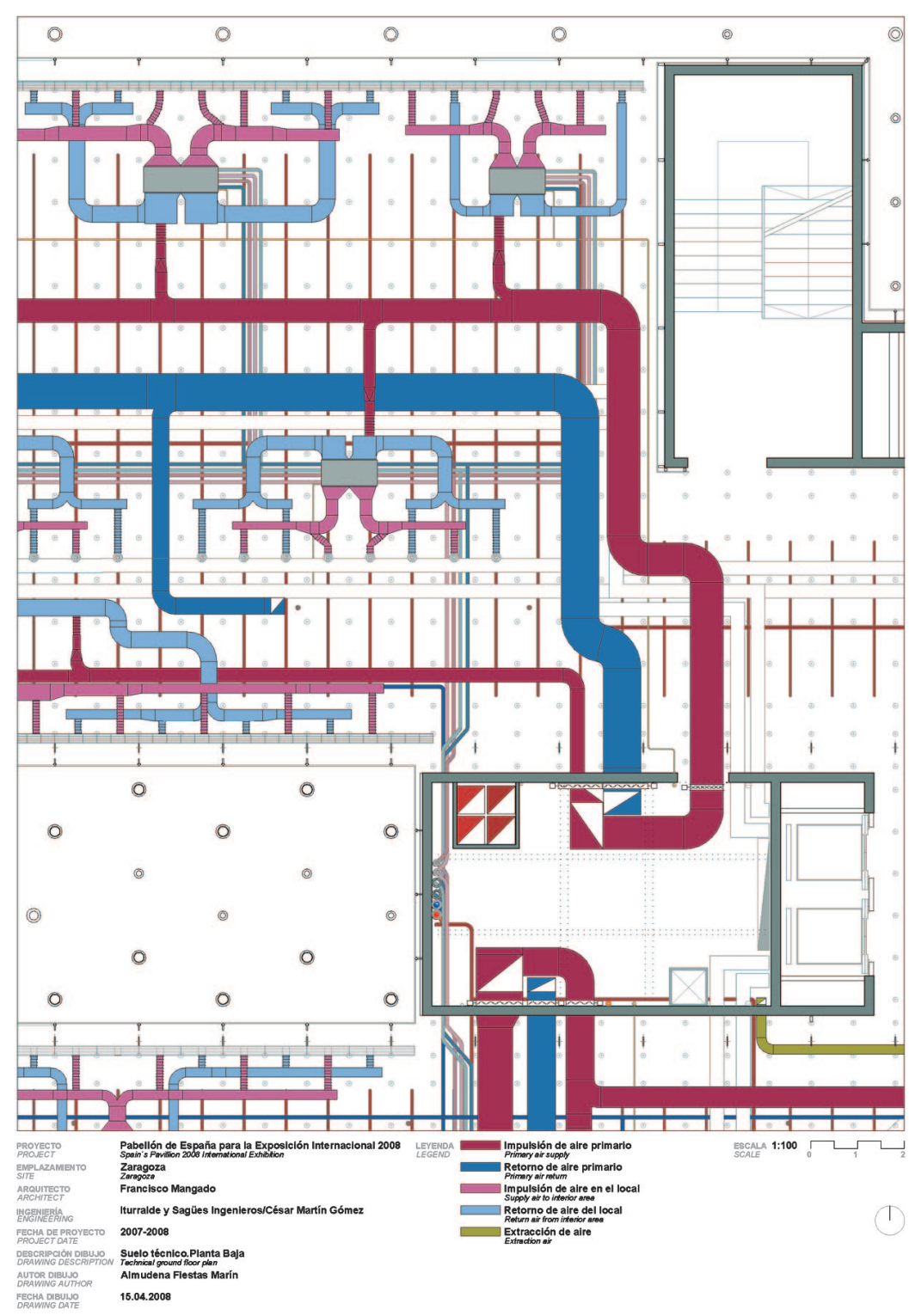

11

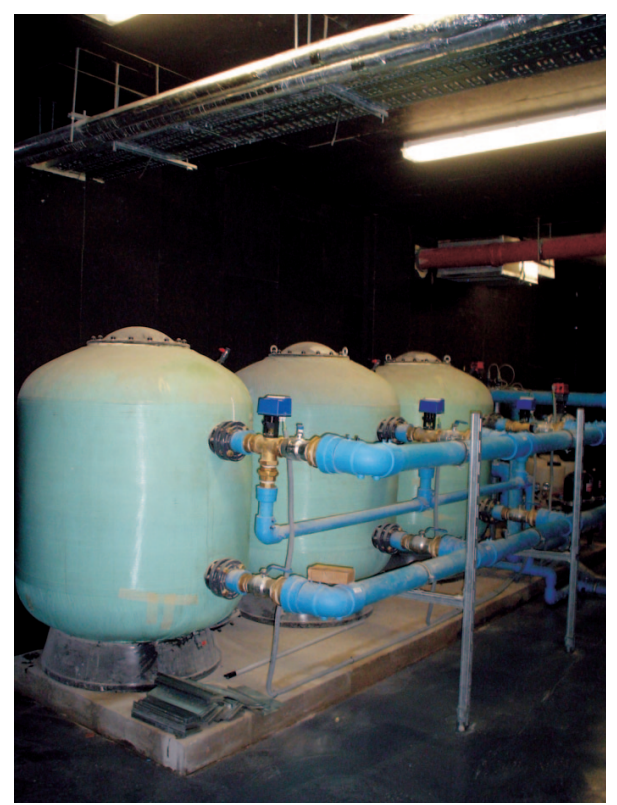

11. Plano con el detalle de montaje de las instalaciones en el falso suelo. 12. Bajante pluvial antes de su colocación (Fot. César Martín Gómez). 13. Sistema de depuración de los estanques ubicado en uno de los locales técnicos del sótano (Fot. César Martín Gómez). 


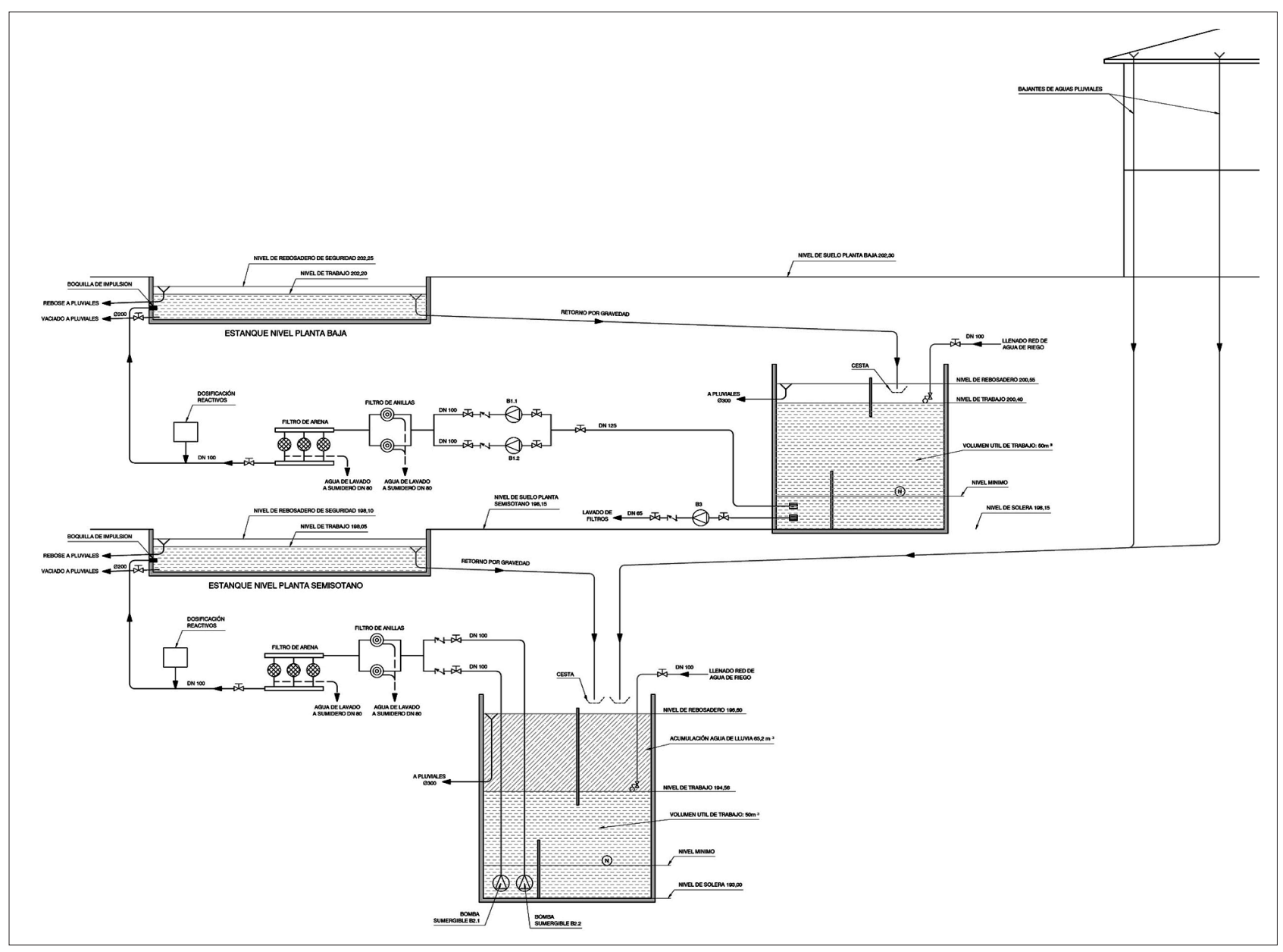

14. Esquema del saneamiento pluvial y de la regulación y depuración del agua de los estanques.
${ }_{5}^{5}$ Dada la ubicación del grupo electrógeno en el edificio y su uso (con un arranque mensual por mantenimiento y en caso de emergencia), así como la distancia a los edificios vecinos, éste elemento no supone ningún problema en términos acústicos como se ha comprobado durante la celebración de la Expo.

6 Evidentemente, en la medida de lo posible, la primera decisión ha sido aprovechar la luz natural para la iluminación de aquellos espacios que durante la Expo y en el uso posterior del edificio así lo requerían. formación para consumir electricidad en baja tensión. Desde el centro de transformación se da alimentación al cuadro general de baja tensión, el cual -a su vez- alimenta los cuadros secundarios de distribución instalados en cada planta del Pabellón. Para cubrir un posible fallo de suministro de energía eléctrica desde la red de la compañía suministradora, y dada la necesidad de atender y garantizar los suministros de seguridad considerados prioritarios (tales como sistemas de control, protección contra incendios, seguridad) se prevé la instalación de un grupo electrógeno de 160 kVA ubicado en la cubierta, facilitando su mantenimiento y minimizando las afecciones acústicas ${ }^{5}$. Para el caso de los ordenadores y servicios especiales, se instala además un sistema de alimentación interrumpida $(\mathrm{SAI})$, que aporta tensión estabilizada sin afección para los equipos.
Por otra parte, con objeto de contar con una red en los equipos de telecomunicaciones libre de ruidos y armónicos, se instala un transformador de aislamiento para la alimentación de los equipos de audiovisuales de las exposiciones. Respecto al cálculo de la potencia eléctrica, ésta se resume en la tabla 1.

\subsection{Iluminación artificial}

Los niveles de iluminación para cada recinto están en función del uso para el que son destinados. La instalación de iluminación artificial proporciona los siguientes niveles medios de iluminación, considerando un factor de mantenimiento del $80 \%{ }^{6}$ :

- Despachos y salas de reuniones: 500 lux - Zonas de exposición: 300 lux

- Restaurantes: 200 lux

Tabla 1

Resumen de la potencia eléctrica del Pabellón

\begin{tabular}{|l|c|c|}
\hline & POTENCIA TOTAL INSTALADA $(\mathrm{kW})$ & POTENCIA MÁX. SIMULTÁNEA PREVISTA $(\mathrm{kW})$ \\
\hline Red & 633 & 411 \\
\hline Red-grupo & 180 & 117 \\
\hline Red limpia & 173 & 133 \\
\hline SAI & 63 & 37 \\
\hline TOTAL & 986 & 662 \\
\hline
\end{tabular}


- Plateau: 1.500 lux

- Zonas de paso: 100 lux

- Aparcamientos: 100 lux

Con objeto de reducir el consumo de energía debido a la iluminación artificial del Pabellón, se toman las siguientes medidas:

- Todos los balastos de luminarias fluorescentes son electrónicos.

- El alumbrado de los aseos se acciona con detectores de presencia.

- Se plantea un sistema de control horario del sistema de alumbrado de las áreas públicas.

Respecto a la iluminación nocturna, especialmente relevante en un evento tan multitudinario como el de la Expo, se ha realizado con luminarias con lámparas leds que iluminaban tangencialmente la lámina de agua, evitando la contaminación lumínica del cielo.

\subsection{Energía fotovoltaica}

En el momento de redacción del proyecto, la colocación de paneles fotovoltaicos no era de obligado cumplimiento, pero se decide su instalación -más allá de los mínimos establecidos posteriormente por el Código Técnico de la Edificación- para ser coherentes con los planteamientos de sostenibilidad requeridos por el autor en el proyecto. Estos paneles fotovoltaicos se instalan en la cubierta, conformando una pérgola que protege las unidades de tratamiento de aire y ventiladores de extracción situadas bajo la misma.

El campo de paneles fotovoltaicos está formado por 372 unidades (cada una con unas dimensiones de 1.310 × $969 \mathrm{~mm}$ y una potencia de $165 \mathrm{Wp}$ ) que consiguen una potencia total instalada de 61,38 kWp.

Toda la energía producida se vierte a la red. Dicha conexión se realiza en el embarrado de baja tensión del centro de transformación de la compañía distribuidora más próximo al Pabellón de España.
Como se plantea en la instalación de agua, también en este caso se monitoriza la producción eléctrica instantánea e histórica de los paneles fotovoltaicos para ser mostrada a los visitantes del edificio.

\section{ACONDICIONAMIENTO}

Se consideran las siguientes condiciones exteriores, de acuerdo con la norma UNE 100014 "Bases para el proyecto - Condiciones exteriores de cálculo":

$$
\text { Verano Invierno }
$$

Temperatura $\left({ }^{\circ} \mathrm{C}\right): \quad 35,6{ }^{\circ} \mathrm{C} \quad-1,1{ }^{\circ} \mathrm{C}$ Humedad relativa: $28,3 \% \quad 86 \%$

Para el cálculo de cargas térmicas, se prevén las siguientes condiciones internas:

$$
\text { Verano Invierno }
$$

Temperatura $\left({ }^{\circ} \mathrm{C}\right): \quad 25{ }^{\circ} \mathrm{C} \quad 21{ }^{\circ} \mathrm{C}$ Humedad relativa: $53 \% \quad 35 \%$

El proyecto inicial del concurso contaba con captadores solares que alimentaban una enfriadora de absorción así como el sistema de producción de agua caliente sanitaria. Posteriormente, dentro de la estrategia energética global adoptada para la Expo, se decide que el Pabellón sea servido desde la central térmica prevista para la Expo. Por tanto, el Pabellón no cuenta ni con producción ni extracción de calor, por lo que la sociedad explotadora de la distribución de calor para el recinto de la Expo se encargó de instalar los intercambiadores de calor en un cuarto técnico propio en el sótano del Pabellón, entre la red exterior de distribución y la red interna, con las siguientes potencias de intercambio:

- Agua enfriada: $850 \mathrm{~kW}$

- Agua caliente: 600 kW

Desde la sala de bombas se alimentan las unidades de tratamiento, unas, de aire primario (zonas de exposiciones) y otras, para las zonas específicas, tabla 2.

\section{Tabla 2}

Características de las unidades de tratamiento de aire: caudales de aire exterior y de impulsión, potencia de las baterías de frío y calor; potencia eléctrica de los motores de los ventiladores

\begin{tabular}{|l|c|c|c|c|c|}
\cline { 2 - 6 } \multicolumn{1}{c|}{} & $\begin{array}{c}\text { Caudal aire } \\
\text { exterior }(\mathrm{m} 3 / \mathrm{h})\end{array}$ & $\begin{array}{c}\text { Caudal impulsión } \\
(\mathrm{m} 3 / \mathrm{h})\end{array}$ & $\begin{array}{c}\text { Potencia batería } \\
\text { de frío }(\mathrm{kcal} / \mathrm{h})\end{array}$ & $\begin{array}{c}\text { Potencia batería } \\
\text { de calor }(\mathrm{kcal} / \mathrm{h})\end{array}$ & $\begin{array}{c}\text { Potencia eléctrica de los motores } \\
\text { de los ventiladores (retorno e } \\
\text { impulsión) }(\mathrm{kW})\end{array}$ \\
\hline Proyección cine & 5.127 & 9.000 & 48.600 & 71.820 & $3+5,5$ \\
\hline Plateau & 5.000 & 10.279 & 53.656 & 76.167 & $4+5,5$ \\
\hline Cocina & 1.400 & 3.500 & 22.344 & 23.940 & $2,2+2,2$ \\
\hline Aire primario norte & 20.011 & 20.011 & 140.000 & 215.040 & $9,2+11$ \\
\hline Aire primario sur & 28.468 & 28.468 & 198.000 & 305.919 & $15+15$ \\
\hline
\end{tabular}


15. Unidades de tratamiento de aire ubicadas en la cubierta del Pabellón bajo los paneles fotovoltaicos (Fotografía: Pedro Pegenaute).

16. Esquema comportamiento fluidodinámico previsto para los huecos motorizados de fachada (simulación). Fuente: Fundación CENERCIEMAT.

17. Ventana motorizada abierta (Fot. César Martín Gómez).

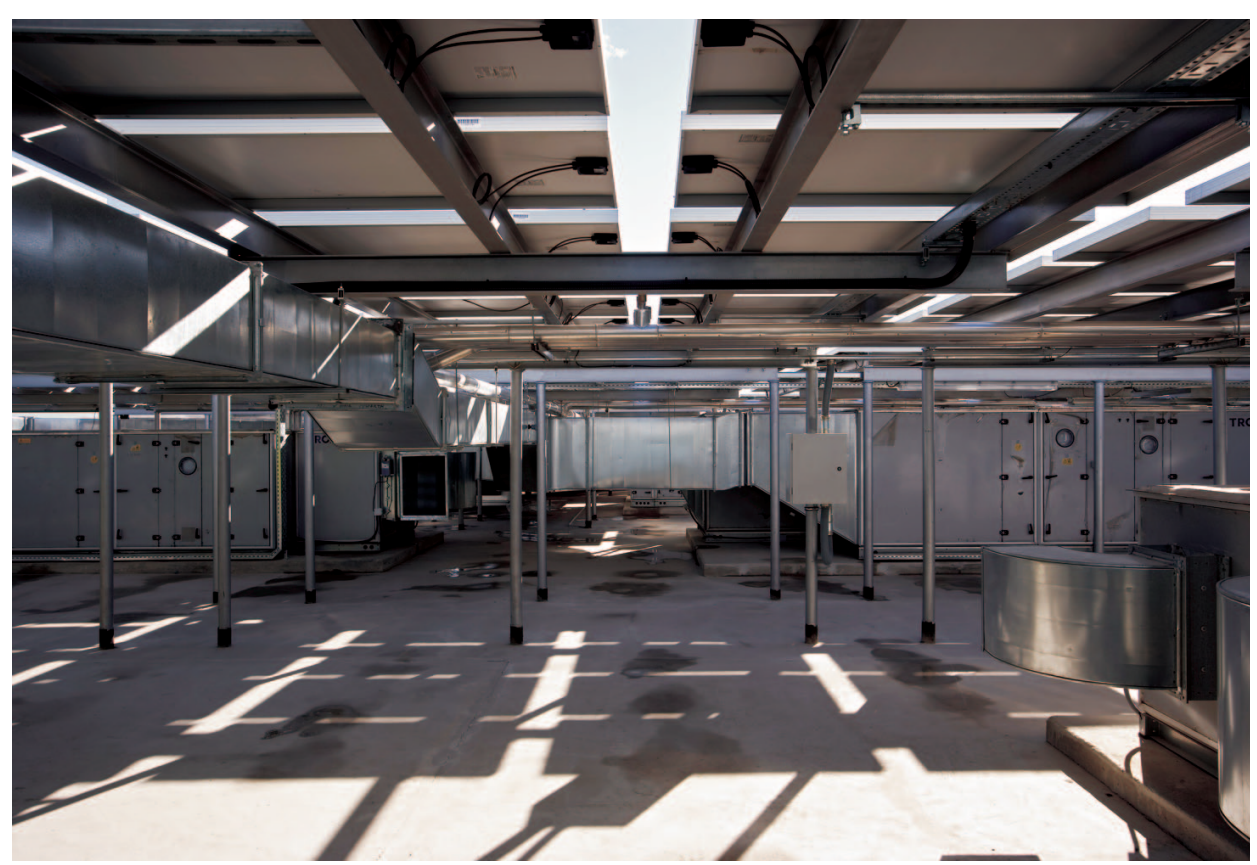

15
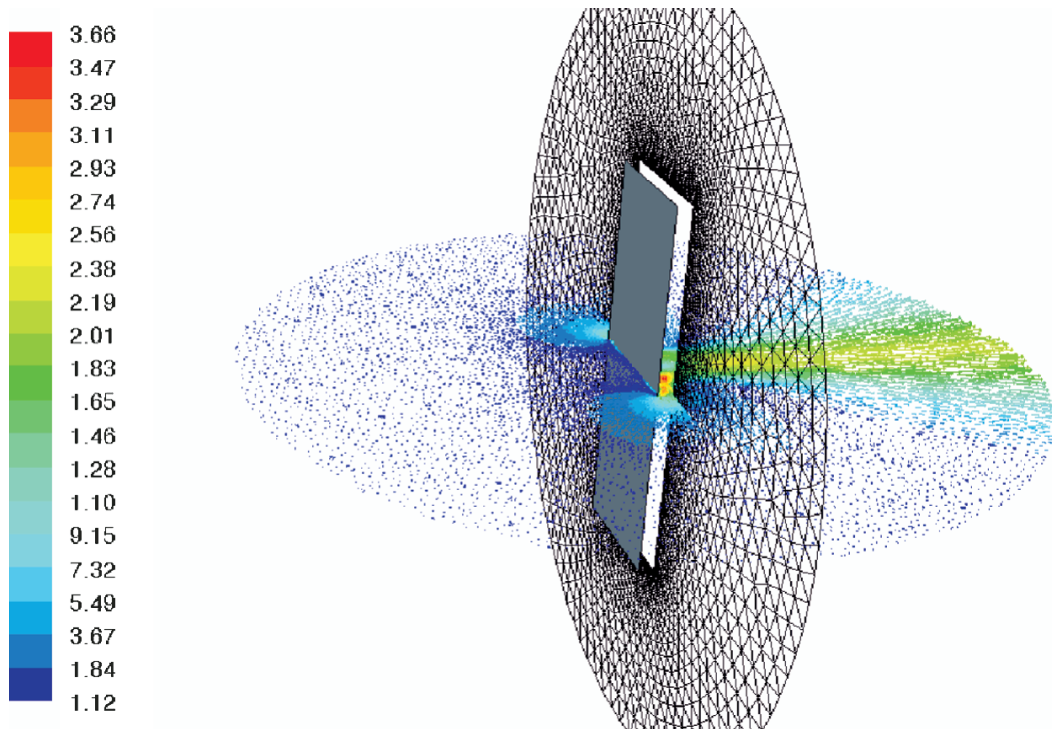

Las unidades de tratamiento de aire se ubican en la cubierta, salvo la del cine, situada en la planta de semisótano. Todas las unidades de tratamiento de aire cuentan con 'free-cooling', para aprovechar las condiciones térmicas exteriores cuando es posible, así como con módulos de recuperación de calor. Las unidades de tratamiento de aire que proporcionan aire primario, lo envían a los fancoils agua-aire instalados en la 'membrana energética' de cada planta. Estos fancoils, que también reciben el agua enfriada y caliente procedente de los intercambiadores (con agua enfriada a $7-15^{\circ} \mathrm{C}$ y con agua caliente a $60-50{ }^{\circ} \mathrm{C}$ ), presentan las siguientes características:

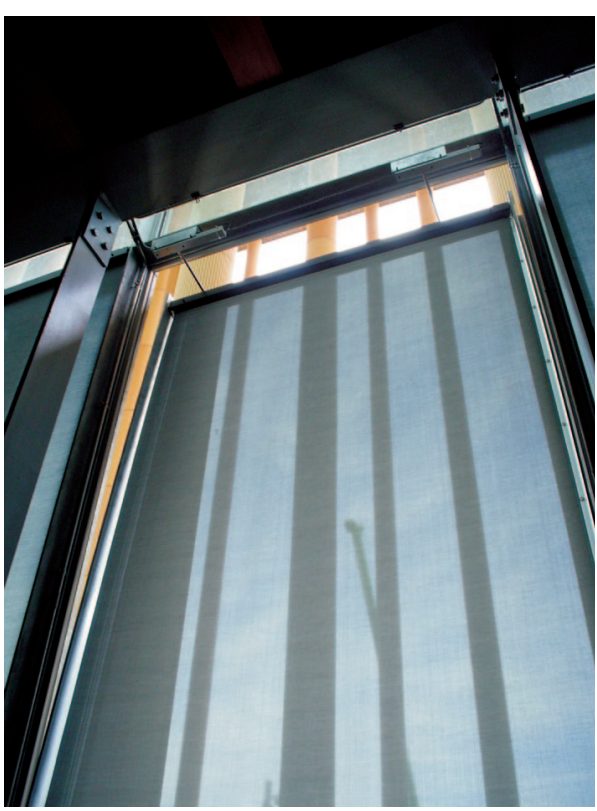

17

- 4 tubos, con batería de agua caliente y de agua fría.

- Ventilador de 3 velocidades.

- Bajo nivel de ruido.

En lo referente a la ventilación pasiva, se plantean huecos practicables en fachadas opuestas (concretamente en las norte y sur), de suelo a techo, de modo que se genera una ventilación cruzada que favorece la refrigeración nocturna, consiguiendo aumentar la disipación de calor durante la noche y así, el edificio presenta una carga térmica menor durante el día, lo que conlleva un menor gasto de extracción de calor durante las horas diurnas. Se plantea el objetivo de reno- 
var el aire interior de los principales locales del Pabellón 5 veces por hora de manera natural7. Esta ventilación cruzada se calculó de dos modos. Primero con herramientas específicas de software de fluidodinámica, y posteriormente se construyó un modelo a escala del edificio para ensayarlo en el túnel de viento del Laboratorio de Aerodinámica 'Ignacio Da Riva', para verificar la medida del efecto de apantallamiento de la densidad perimetral de los pilares sobre los huecos practicables de la fachada.

\subsection{Soportes generadores de microclimas $^{8}$}

El agua de lluvia acumulada, además de servir para las láminas de agua exteriores, también alimenta el agua necesaria para el funcionamiento de los 'soportes generadores de microclimas'. Esta definición se refiere a uno de los elementos menores del Pabellón en relación al conjunto, pero que, sin embargo, es de los que más impacto mediático ha tenido.

El origen de la solución empleada en estos soportes está en la refrigeración evaporativa, un efecto para reducir la temperatura ambiente empleado desde hace siglos en climas como el mediterráneo, con veranos secos, y que se utilizó, por ejemplo, para aliviar el calor de los espacios exteriores de la Expo de Sevilla.

En este caso, en la Exposición Internacional del Agua, el Pabellón muestra, como una exposición más de las que se ven en el interior, las posibilidades de acondicionamiento con el propio agua, realizándose aquí al forzar el movimiento de aire con agua vaporizada que moja la cerámica por el interior de algunos de los pilares ubicados en la zona de acceso ${ }^{9}$. Dadas las particularidades de esta instalación, ha de prevenirse el riesgo de crecimiento de la bacteria 'Legionella pneumophila' aunque, como se afirma en el capítulo "Evaporative Air Cooling Equipment" de la "ASHRAE System and Equipment Handbook", los enfriadores evaporativos no proporcionan la condiciones adecuadas para el crecimiento de la bacteria 'Legionella pneumophila' además, la temperatura del agua va a tender a estar por debajo del rango de temperaturas de crecimiento de la 'Legionella', a lo que se suma que en los SGMs no se va a producir recirculación del agua.

Por tanto, sería raro que el crecimiento de 'Legionella' se diera bajo las condiciones anteriores.

En cualquier caso, debido a la dureza del agua de Zaragoza y a la formación de bio-
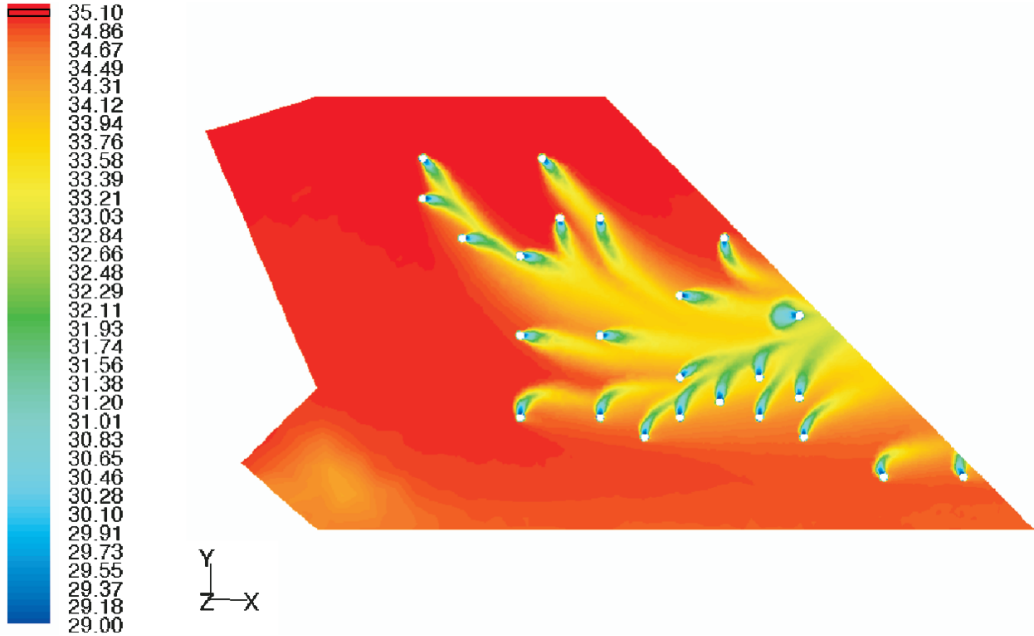

$\underset{Z}{Y} X$

18

capas (inherente a los procesos que usan agua) se realizó un prolijo protocolo de mantenimiento y tratamiento del agua (que incluía la dosificación cada cierto tiempo de cloro y polifosfatos a la red de agua que alimentaba los SGMs) para así reducir al mínimo posible los riesgos de crecimiento y transmisión de la Legionella.

\section{INSTALACIONES ESPECIALES}

\subsection{Seguridad y megafonía de emergencia}

Debido a los requerimientos de seguridad del programa, se colocan cámaras de vigilancia y detectores de presencia que controlan tanto el acceso de personas como de vehículos.

Se dispone de un sistema de megafonía para emergencia que cubre la totalidad del Pabellón, a través del cual se pueden dar alarmas locales, avisos de alarma general e instrucciones verbales.

La central de megafonía está supervisada y monitorizada por ordenador, y tiene conexión con el puesto de control general de la Expo, a través de la red informática general.

Además, todas y cada uno de los locales, sean despachos o zonas de exposiciones, disponen de megafonía. En aquéllos el control de volumen se realiza con un potenciómetro por dependencia.

\subsection{Ventilación y extracción de humos en aparcamientos}

En el aparcamiento se realiza una instalación de ventilación forzada que cumple las funciones siguientes:

- Impulsión de aire limpio y extracción de aire viciado en funcionamiento normal.

- Extracción de humos en caso de incendio.
18. Contornos de temperatura a 1,5 metros del suelo para una velocidad de viento de $1 \mathrm{~m} / \mathrm{s}$ (Fuente: Fundación CENER-CIEMAT). suponiendo una velocidad promedio de viento en el entorno urbano de $2 \mathrm{~m} / \mathrm{s}$, con una tasa media de renovación por viento de 8,5 renovaciones hora; a esta tasa hay que añadir el movimiento de aire causado por la convección natural. El accionamiento mecánico de las ventanas se realiza con un sistema de control horario ubicado en los cuadros eléctricos que gobiernan los motores de las ventanas.

${ }^{8}$ El funcionamiento detallado de estos elementos puede consultarse en: D. Lanceta, C. Martín Gómez, D. Martínez, F. Serna. "Cooling of outdoor spaces by mean of evaporative-cooling ceramic pilars". AIVC 28th Conference and Palenc 2nd Conference: Building Low Energy Cooling and Ventilation Technologies, 27-29 September 2007, Crete Island, Greece.

${ }^{9} \mathrm{El}$ movimiento de aire se realiza con dos ventiladores, uno de 5,5 kW y otro de $11 \mathrm{~kW}$.
Es un objetivo que se alcanza 


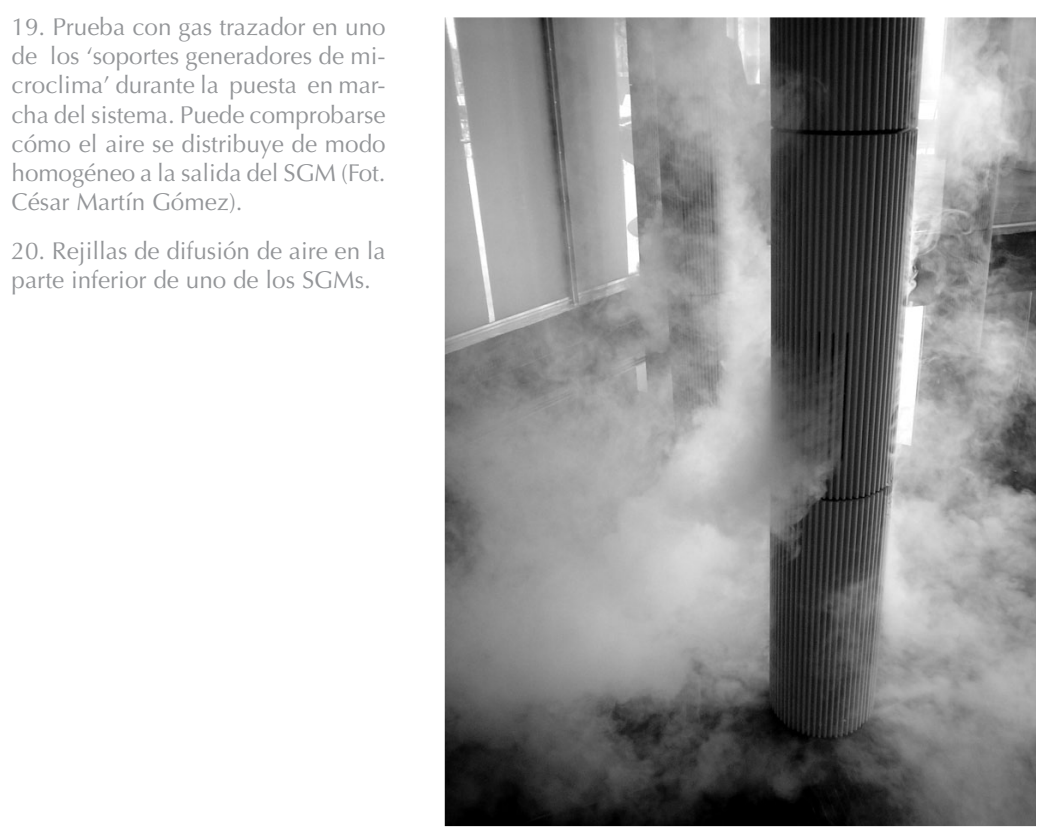

19

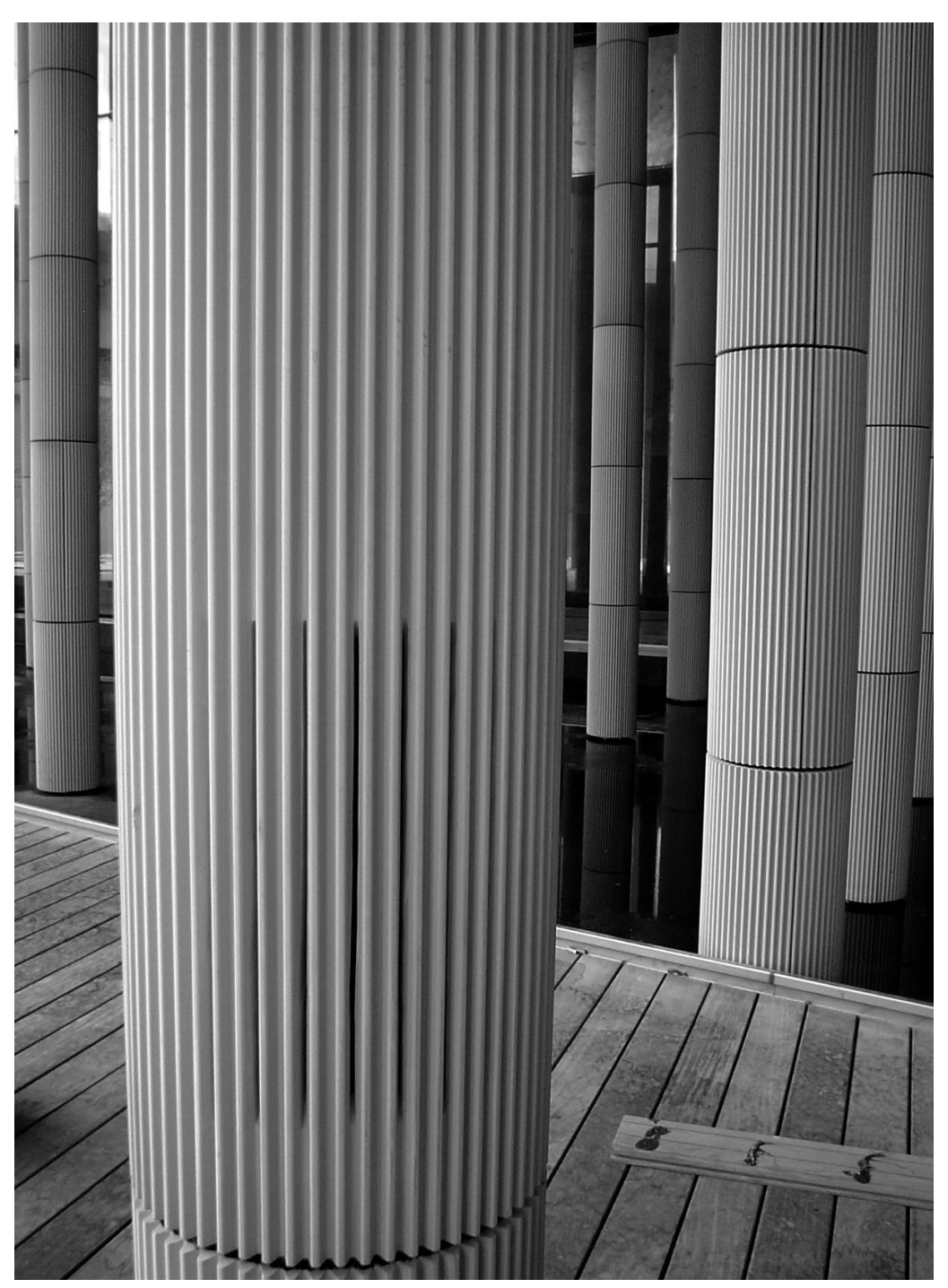

Se instalan dos ventiladores para extraer el aire, capaces de proporcionar un caudal de seis renovaciones por hora, soportando humos a $400{ }^{\circ} \mathrm{C}$ durante dos horas; los dos ventiladores de impulsión de aire limpio tienen el mismo caudal. Los cuatro ventiladores se ubican en el sótano del Pabellón.Los ventiladores están accionados por un sistema automático de detección de $\mathrm{CO}$ y de detección de incendios, y están acoplados a una red de conductos de impulsión y extracción que llegan a la cubierta del edificio. Estos conductos están protegidos con un revestimiento resistente al fuego durante dos horas en su paso por otros sectores de incendio.

\subsection{Control}

Se realiza una división por zonas del sistema de regulación y control que además de permitir una optimización de las instalaciones, sirve para realizar el seguimiento y monitorización de los sistemas de instalaciones implantados en el Pabellón. El sistema de control integra todas las instalaciones que componen el Pabellón por software (incendios, sistema de depuración, acondicionamiento, cámaras de vigilancia, megafonía,...) y se encarga de regular, parametrizar, monitorizar y registrar alarmas, curvas de tendencia, tablas de históricos e informes de todas las variable medidas desde el ordenador de control general.

Así, aunque no es objeto de este artículo describir los detalles de los elementos de la instalación de control, se describen a continuación las principales funciones realizadas por la instalación de control:

- Monitorización del agua consumida y de la electricidad producida en los paneles fotovoltaicos, generando información sobre el sistema que es presentada al público del Pabellón, tal y como se ha visto en los apartados anteriores.

- Mando y regulación de las bombas de agua enfriada y caliente.

- Mando y regulación de las temperaturas y humedad relativa de impulsión de todas las unidades de tratamiento de aire en función de las condiciones de los locales a los que sirven y de las del aire exterior.

- Regulación de la temperatura de los locales mediante mando sobre las cajas de volumen de aire variable previas a los fancoils.

- Mando de los extractores de ventilación.

- Monitorización del sistema completo de acondicionamiento.

- Control y monitorización de la instalación de enfriamiento de ambiente exterior.

- Archivo de datos de todas las variables del sistema de climatización y generación de históricos, cálculo de rendimientos y generación de informes. 
- Monitorización y registro de las alarmas de incendios y del sistema de seguridad.

- Transmisión e intercambio de datos con el sistema centralizado de control de Expo Zaragoza a través de la red de comunicaciones general.

\section{CONCLUSIONES}

Los objetivos del concurso inicial de lograr un edificio con un bajo consumo energético se han mantenido durante el proyecto de ejecución hasta llegar al PabeIlón construido, todo lo cual hace que el Pabellón constituya un avance claro en el plano arquitectónico y energético, pues no es habitual que soluciones tan diversas se realicen en un único edificio y que además los resultados energéticos se expongan directamente a los usuarios del edificio. Tanto es así, que puede decirse que todas las soluciones activas y pasivas planteadas han resultado un éxito.

La mejor prueba de la validez de la afirmación anterior es que, tras las visitas de decenas de miles de personas al Pabellón durante la Expo, la demanda de frío no ha llegado a las puntas previstas en los ajustados cálculos del proyecto de ejecución, en buena parte debido al buen funcionamiento de las ventilaciones nocturnas, al atemperamiento producido por las láminas de agua, así como a la efectividad de los elementos de sombra instalados.

Los bajos costes de mantenimiento tras los intensos meses de la Expo, también avalan la calidad de los materiales utilizados y de la sensatez de las soluciones constructivas empleadas. A este respecto, el concepto de construcción espacial que supone la 'membrana energética', a pesar de las complejidades de su puesta en obra, se ha revelado como una solución eficaz para su aplicación en otros edificios de uso polivalente.

También ha de destacarse la colaboración multidisciplinar que se produjo desde los primeros croquis del concurso, y que enriqueció notablemente las soluciones del proyecto con las aportaciones de arquitectos, ingenieros de distinto perfil, químicos,... hasta llegar, como se ha visto, a utilizar incluso los conocimientos procedentes del campo aeronáutico. Llegados a este punto, se observa cómo para describir el Pabellón de España no ha sido necesario mencionar el concepto de 'arquitectura bioclimática' en ningún momento.

El Pabellón ejemplifica como los arquitectos e ingenieros involucrados en los procesos de edificación, no han de realizar ensayos inútiles sobre prototipos no extrapolables a

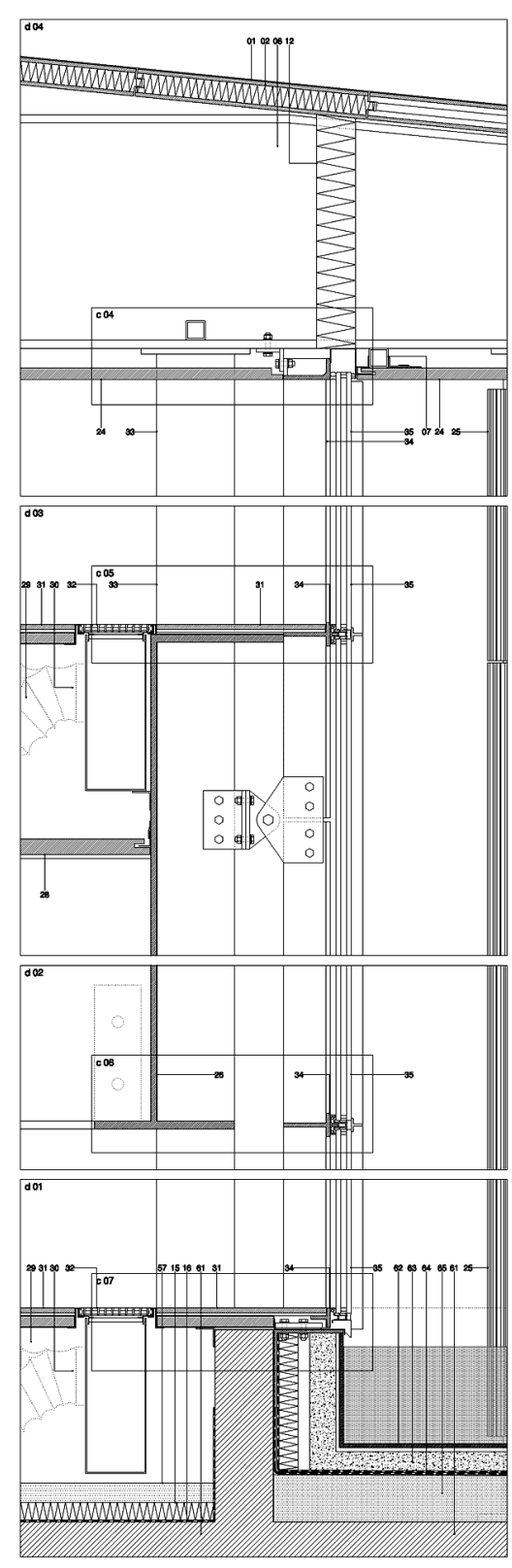

21. Detalles constructivos 1.

la realidad: la sociedad exige un compromiso a estos profesionales para construir lo correcto y no hacer investigación en papel sin repercusión real. La coherencia en la implantación de todos los sistemas hasta aquí detallados ha permitido la consecución de un edificio emblemático desde los aspectos energéticos, con una notable reducción del consumo energético respecto a otros edificios convencionales de similares características y con la misma superficie ${ }^{10}$; medioambientales (con importantes reducciones de emisiones de $\mathrm{CO}_{2}$, bajo impacto ambiental y reducción del consumo de recursos naturales) y relativo al bienestar, facilitando que el Pabellón de España se haya convertido en un punto de encuentro y de relación de los visitantes a la Exposición Internacional de Zaragoza.

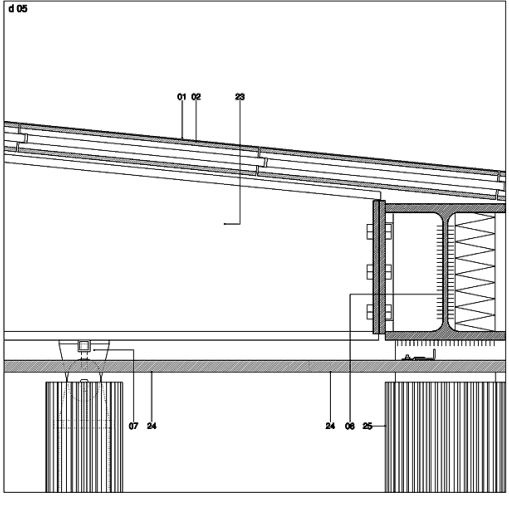

Formación de cubierta: lámina impermeabilizante de caucho sintético EPDM vulcanizado de $1.14 \mathrm{~mm}$.esp. tipo FIRESTONE Rubbergard Max siva.

Formación de cubierta: panel sándwich tipo TEZNO-CUBER con cara superior de tablero contrachapado hidrófugo de $16 \mathrm{~mm}$ esp.
núcleo aislante de lana de roca mineral de $60 \mathrm{~mm}$. y cara inferior de tablero de fibras de madera reciclada de $10 \mathrm{~mm}$ esp. sobre entramado estructural.

Entramado estructural para formación de cubierta inclinada de perfil tubular galvanizado 50.50 .4

4. Formación de canalón oculto de $15 \times 30 \mathrm{~cm}$ con cajeado de tablero de DM hidrófugo acero galvanizada plegada de $2 \mathrm{~mm}$ esp. acero galvanizada plegada de $2 \mathrm{~mm}$ esp. chapa de acero galvanizada plegada de 2 mm esp. sobre lámina impermeabilizante soporte de tablero de DM hidrófugo de 20 mm esp.

Vigas metálica de cubierta: HEB $600 \mathrm{~s} /$ plano y especificaciones técnicas.

Correa de perfil tubular de 50.50 .

Armado metálico de costilla: palastro de altura variable s/detalle y $10 \mathrm{~mm}$. esp con cificaciones técnicas.

Perfil de confinamiento HEB 340 s/planos especificaciones técnicas

Chapa metálica de $15 \mathrm{~mm}$ de espesor s/planos y especificaciones técnicas

Forjado de chapa colaborante PL59/150 Aceralia : $\mathrm{h}>4 \mathrm{~cm}$ y $0.8 \mathrm{~mm}$ espesor s/plano y especificaciones técnicas

na de roca mineral de $50 \mathrm{~mm}$ y $80 \mathrm{~kg} / \mathrm{m}^{3}$. tipo URSA Glasswool P0081

13. Formación de cubierta superior de panel fotovoltaico con cara frontal de vidrio templado de alta transmisividad $y$ cara posterior con
tedlar de varias capas s/planos y especificaciones técnicas.

14. Entramado estructural de cubierta superior: correas perfil IPE 140 S/planos y especificaciones técnicas.

15. Membrana impermeabilizante: lámina de Caucho vulcanizado EPDM de $1.5 \mathrm{~mm}$ esp. tipo FIRESTONE Rubbergard y capa separa-

6. Aislamiento térmico de plancha de corcho aglomerado de $50 \mathrm{~mm}$.esp. sellado y fijado con juntas a tope con manta geotextil supecon
rior.

17. Terminación de cubierta: resina proyectada Conipur 255.

18. Reja de celosía metálica galvanizada tipo TRAMEX con pletina de acero de $20 \times 2 \mathrm{~mm}$, formando cuadrícula de $30 \times 30 \mathrm{~mm}$. Con

zado.
Carpintería de cierre perimetral de perfil tubular de acero galvanizado $40.8 .2 \mathrm{~mm}$ atornillado y doble vidrio de Seguridad tipo Jofebar de 10+10 mm esp. con interposición de butiral de polivinilo incoloro translúci do.

20. Pilar metálico de estructura cubierta de 90 $\mathrm{mm}$ diam. y 6 mm.esp. s/ planos y especificaciones técnicas.

21. Formación de pendiente con hormigón Capa de mortero de cemento de $20 \mathrm{~mm}$ esp. to interior de chapa galvanizada de $3 \mathrm{~mm}$ to interior de chapa galvanizada de $3 \mathrm{~mm}$
esp. y doblada en $150 \mathrm{~mm}$ diam. $\mathrm{s} /$ planos $y$ especificaciones técnicas.

${ }^{10}$ De acuerdo con el informe elaborado al respecto para el proyecto por el Departamento de Arquitectura del Centro Nacional de Energías Renovables. 


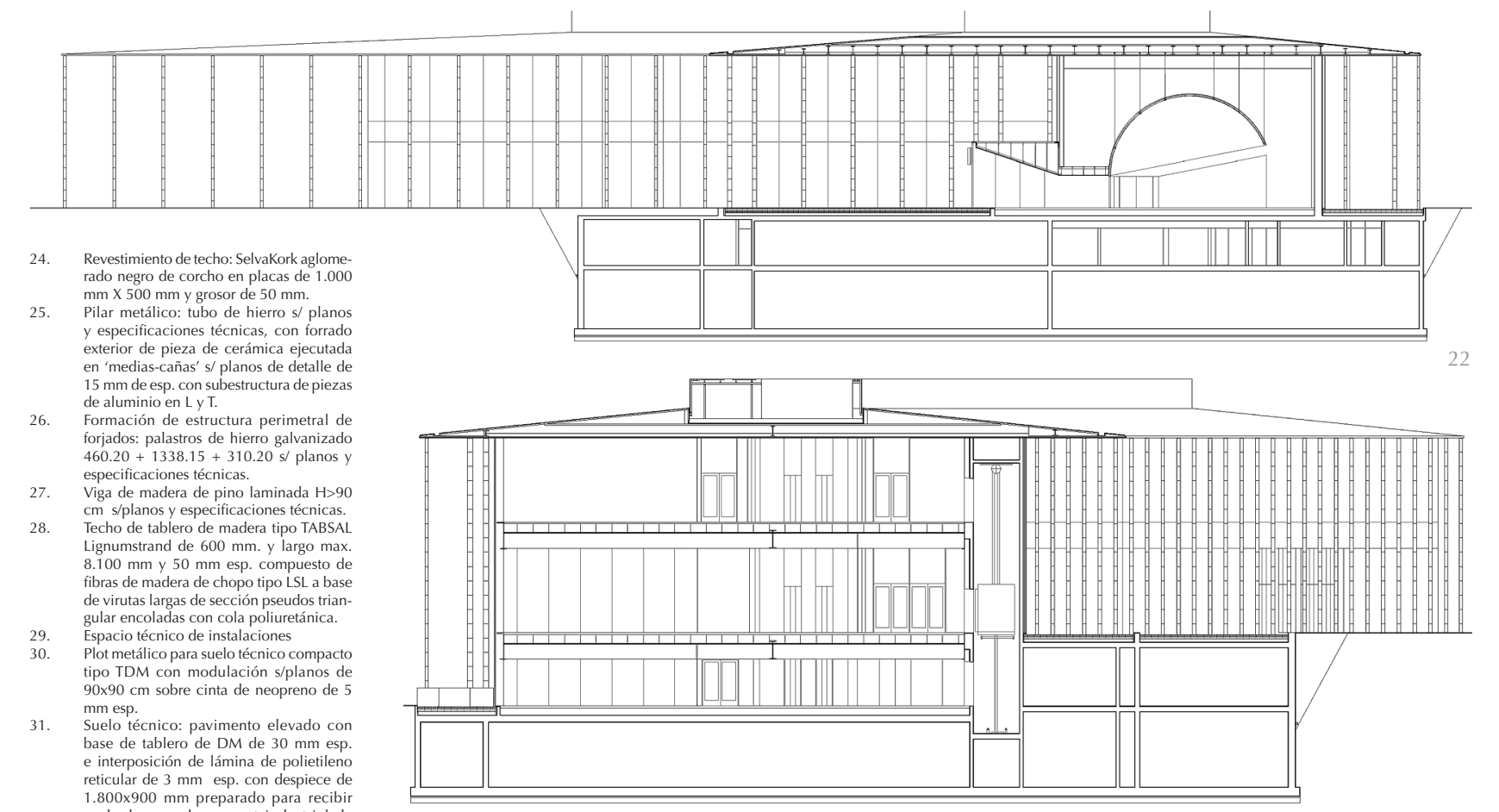

acabalo sup. de prque industrial de acabado sup. de parquet industrial de encolada formada por $20 \mathrm{~mm}$, de espesor $10 \mathrm{~mm}$ de anchura, $260 \mathrm{~mm}$ de longitud con acabado horneado y aceite de jensen. Reja de impulsión de aire acondicionado calefacción de $200 \mathrm{~mm}$ tipo TROX serie AF con parrilla de lamas lineales atornillada base y marco de acero inoxidable acabado

33. Tirante metálico s/planos y especificaciones técnicas: palastro de $200.20 \mathrm{~mm}$

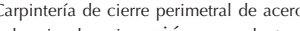
galvanizado: ejecución en palastros vertical y horizontal s/despiece en planos exterior en perfil según especificaciones técnicas.

35. Doble acristalamiento térmico tipo 'Climalit' formado por vidrio exterio de Seguridad laminado 6+6 mm esp. cámara de aire $15 \mathrm{~mm}$.esp. + vidrio interior de seguridad laminado $6+6 \mathrm{~mm}$ esp. con interposición de butiral de polivinilo transparente incoloro

lemiento térmico tipo 'Climalit' formado por vidrio exterio de Seguridad laminado 6+6 mm.esp. rior de Seguridad mm.esp. + vidrio intecon interposición de butiral de polivinilo translúcido en luna interior.

Muro de hormigón armado s/planos y especificaciones técnicas.

Formación de estructura perimetral de forjados: palastros de hierro galvanizado ciones técnicas.

cines de palastro metálico S/planos y especificaciones técnicas con platabanda embebida en muro de hormigón de $640.15 \mathrm{~mm}$. Tabique de bloques de hormigón gris de $40 \times 20 \times 20$ o de $40 \times 20 \times 10$ según zonas recibido con mortero de cemento $y$ aren

Revestimiento de muro con vidrio de Seguridad laminado de $8+8 \mathrm{~mm}$ esp con interposicin de butral de polivilo conformada en frío de acero galvanizado conformando retícula $\mathrm{s} /$ detalles.

Trasdosado de doble placa de cartón yeso tipo PLADUR de $13+13 \mathrm{~mm}$. esp. colocado a rompejuntas y preparado para pintar fijado a estructura de perfilería tipo $C$ galvanizada. Relleno interior segun zonas de lana de vidrio de $45 \mathrm{~mm}$.esp. tipo URSA

43. Rodapiés de DM para pintar de 80×12 mm y terminación superior a tope con ángulo

d 22a
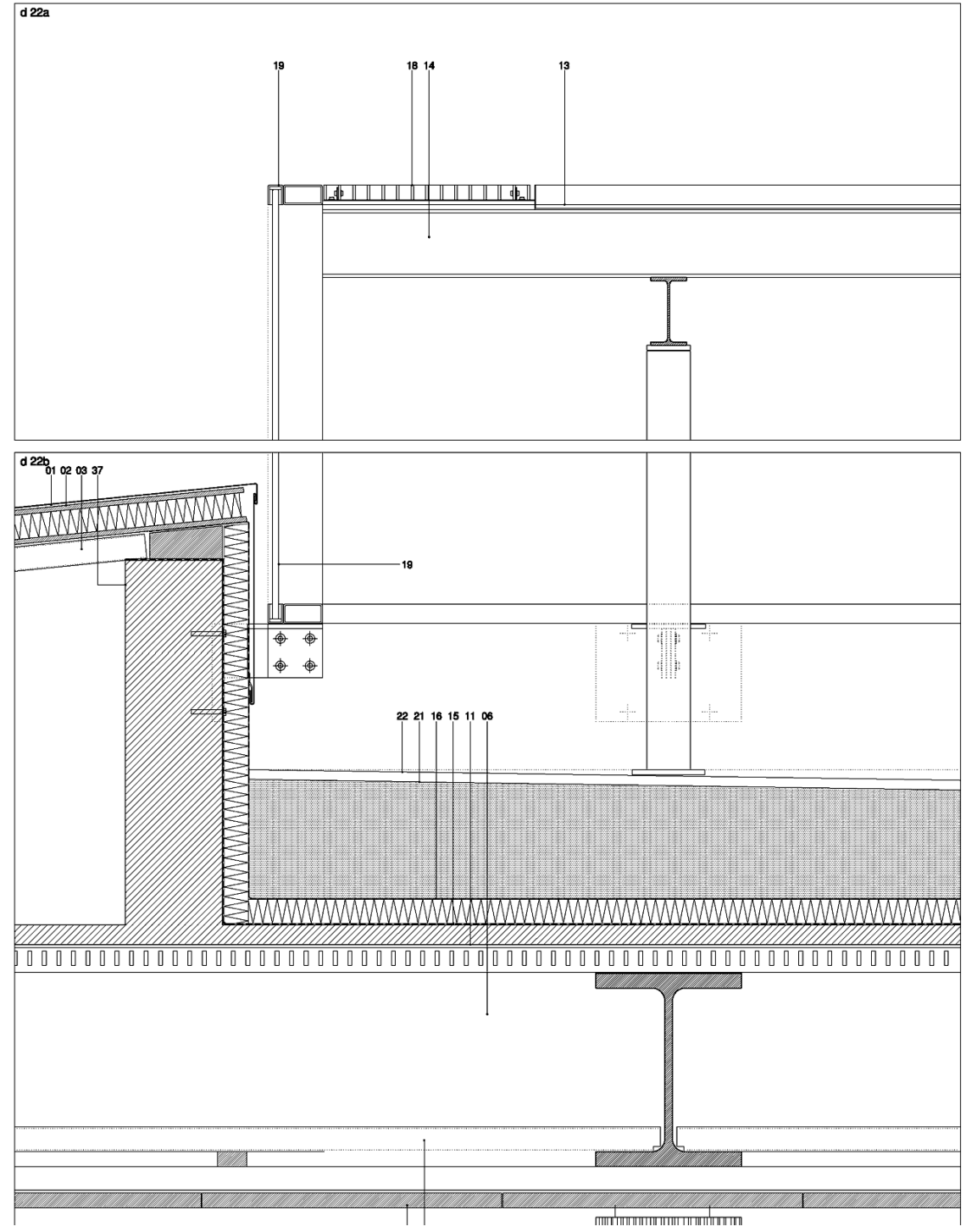

23. Sección transversal.

24. Detalles constructivos 2 


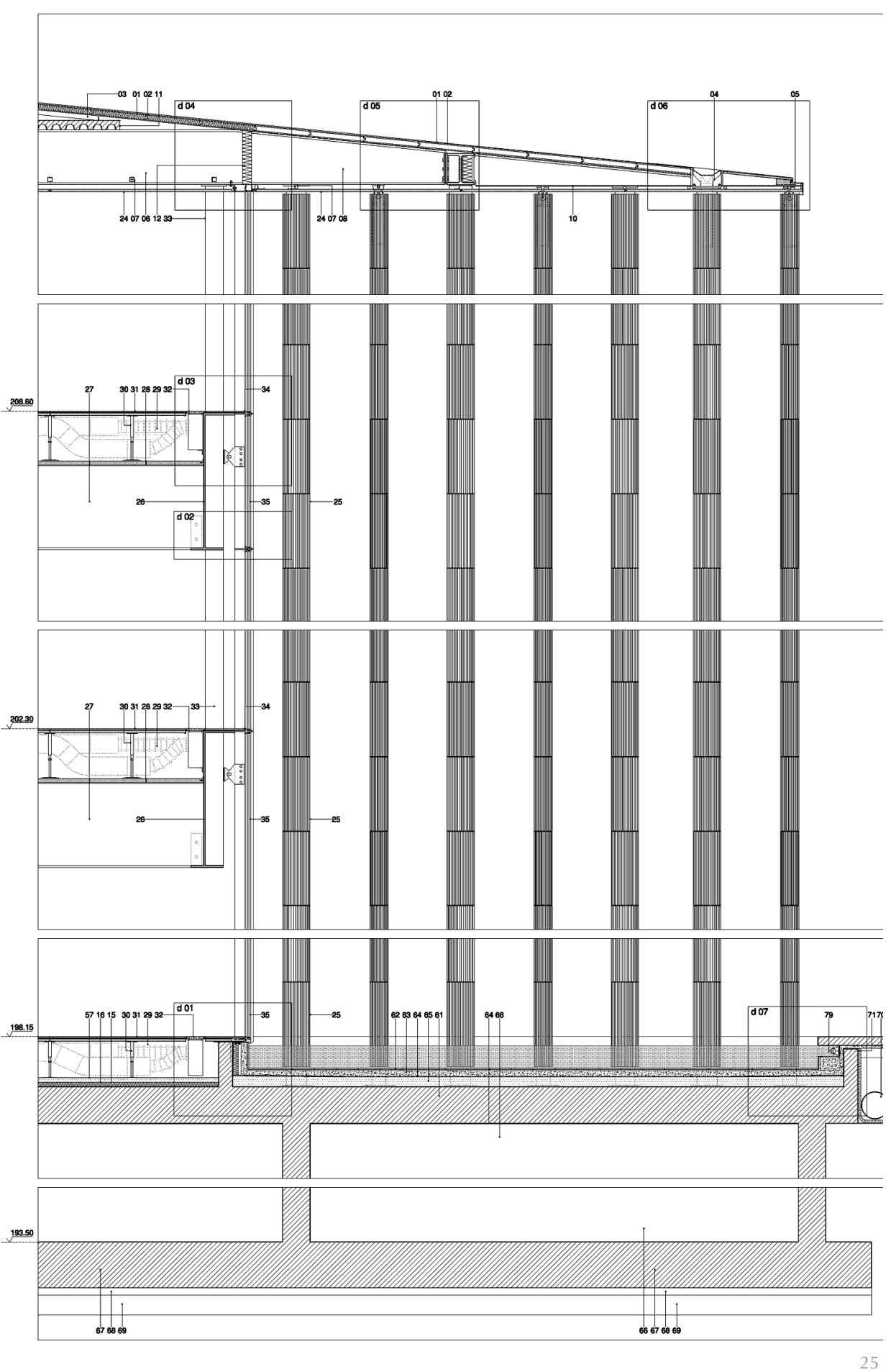

44. Tabique y/o revestimiento interior con placa de cartón yeso de $13 \mathrm{~mm}$ esp. tipo PLADUR fijada a estructura de perfilería tipo C galvanizada y
revestimiento de panel de DM hidrófugo de $20 \mathrm{~mm}$ esp. Juntas a tope y preparado para pintar s/ definición de la DF.

45. Apoyo

46. Tabique interior de doble placa de placa de cartón yeso de $13+13$ mm esp. a ambas caras tipo PLADUR fijada a estructura de perfilerí tipo C galvanizada colocado a rompejuntas. Preparado para pintar P0081.

47. Alicatado de gres de pasta blanca vitrificado CINCA, serie Nova Arquitectura de $20 \times 20 \mathrm{~cm}$. precortado en piezas de $10 \times 5 \mathrm{~cm}$ y color jasmin, recibido con pasta adhesiva sobre doble placa de cartón yeso hidrófugo de $13+13$ mm

48. Revestimiento de espejo plateado tipo MIRALITE EVOLUTION con vidrio PLANILUX de $5 \mathrm{~mm}$ esp. sobre tablero de DM hidrófugo de 20 $\mathrm{mm}$ esp. y rastreles de

4. Falso techo continuo suspendido de placa de cartón yeso tipo PLAaislamiento acústico de panel de lana de vidrio tipo URSA Glasswool P0081 de $45 \mathrm{~mm}$ esp.

50. Suelo de entablonado machihembrado de madera de roble horneado de $20 \mathrm{~mm}$.esp. c/tratamiento antihumedad adherido a base de tablero de DM de $30 \mathrm{~mm}$ esp. e interposición de lámina acústica intermedia de polietileno reticular.
51. Suelo de resina SIKAFLOOR, con doble imprimación Sikafloor-156 + capa de mortero autonivelante Sikafloor 261 de $2 \mathrm{~mm}$ esp. y color a definir por la DF serie Nova Arquitectura de $20 \times 20 \mathrm{~cm}$ precortado en cuatro piezas de $10 \times 10 \mathrm{~cm}$, antideslizante y color a definir por la DF

53. Suelo técnico de celosía metálica galvanizada tipo TRAMEX con pletina de acero de $20 \times 2$ mo electro-soldadas y posterior galvanizado.

Suelo exterior tipo EXTERPARK Classic de tarima de madera maciza de acero inox Separación de rastrel cada $50 \mathrm{~cm}$. Repláfugo y clip PM de definir por la DF

55. Suelo de placa de hormigón prefabricado de árido calizo y siliceo, aglomerado con marmolina y cemento blanco de $45 \mathrm{~mm}$ esp. Peldaño formado por placa de hormigón prefabricado de ancho hasta $2.5 \mathrm{~m}$ de árido calizo y siliceo, aglomerado con marmolina y cemento blanco de $45 \mathrm{~mm}$ esp. recibido con mortero cola.

57. Solera de nivelación de espesor variable con hormigón HA25/p/20/lla y

Solc cegularización de mortero de

59. Tabiquillo aligerado de ladrillo cerámico hueco de $24 \times 11 \times 7$ recibido con mortero de cemento $\mathrm{M} 40$.
52. Suelo de baldosa cerámica de gres de pasta blanca vitrificado CINCA
25. Sección constructiva.

60. Solera nivelada pulida en color a definir por la DF y de $10 \mathrm{~cm}$ esp. con adición de RODASOL Cuarzo Corindon tipo COPSA lamina de polietileno galga 400 entre base de hormigon armado y hormigón de solera. Losa de hormigón armado s/ planos y espe-

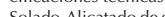

Solado-Alcatado de gres CINCA serie 'Pool', estructura alveolar $11.5 \times 24 \mathrm{~cm}$ recibida con mortero cola sobre recrecido de mortero de cemento hidrófugo.

63. Formación de vaso de piscina: capa de hormigón gunitado de $5 \mathrm{~cm}$ esp. y fraguado rápido y armadura de doble malla electrosoldada.

64. Impermeabilización con lamina impermeabizizante de caucho sintético EPDM vulcanicolocación flotante y geotextil de fibra de poliéster de $120 \mathrm{~g} / \mathrm{m}^{2}$ Geoflex 120 ASFALTEX. Formación de pendiente con hormigón H150.

66. Relleno, extendido y compactado de tierras propias a cota s/detalles.

Losa de cimentación de hormigón armado de $50 \mathrm{~cm}$ esp. s/planos y especificaciones

68. Capa de hormigón en masa $\mathrm{HM}-20 / \mathrm{P} / 40$ / lla para limpieza y nivelado de fondo de cimentación.

69. Encachado de base de $20 \mathrm{~cm}$ de esp. con grava caliza de granulometría $40 / 80 \mathrm{~mm}$ y

70. Drenaje perimetral y de muros en sótano con tubo de pvc de $300 \mathrm{~mm}$ diam. colocado sobre base de arena y relleno de tubería con grava de granulometría $40 / 80 \mathrm{~mm}$.

Impermeabilización de muros con emulsión asfáltica y membrana impermeabilizante de betún modificado con elastomero + capa densidad con geotextil incorporado.

Barandilla de escalera de chapa lisa de $2 \mathrm{~mm}$. esp. plegada y fijada a bastidor portante $\mathrm{de}$ perfil tubular 40.40 .3 anclado a estructura de losa de hormigón armado de escalera. Acabado a definir por la DF.

Pasamanos de escalera de chapa lisa de $2 \mathrm{~mm}$.esp. plegada y fijada a pletina de hierro hormigón armado. Acabado a definir por la horm
DF.

74. Estructura metálica de puentes: HEB 340 planos y especificaciones técnicas fijados extremos a perfil armado de acero laminado en L.
Correa IPE 120 de soporte de pavimento en

puentes.
Acristalamiento de seguridad formado por doble vidrio laminado tipo Stadip $10+10 \mathrm{~mm}$ esp. extra-claro con interposición de butira de polivinilo transparente incoloro.

Pletina calibrada de acero laminado cajón de soporte de carpinterís y puentes: $50.10+645.10+645.10+310.10$.

78. Formación de iluminación en techo: luminaria estanca s/planos y especificaciones técnicas incluida en cajeado de placa de cartó yeso de $15 \mathrm{~mm}$ esp. con difusor inferior de policarbonato translúcido de $8 \mathrm{~mm}$.esp. marco perimetral de acero inoxidable. Luminaria sumergida estanca de led's zow concuerdo de aluminio extraído y cobertura de policarbonato.

80. Reja de retorno de aire acondicionado/ calefacción de $200 \mathrm{~mm}$ tipo TROX serie AF con parrilla de lamas lineales atornillada base y marco de acero inoxidable acabado mate.

81. Tabique perimetral en formación circula con doble placa de cartón yeso tipo PLADUR de $13+13 \mathrm{~mm}$ esp. colocado fil the-juntas con estructura interior de perde Lana de vidrio de 80 mm esp tipo URSA Glasswool P0081.

82. Semiesfera de proyeci a definir por la DF. con estructura metálica interior y fijación a tirantes de acero laminado s/especificaciones técnicas.

83. Palastro metálico de $15 \mathrm{~mm}$ esp. en formación de cierre lateral de carpintería s/detalles

84. Sumidero/rebosadero ejecutado en chapa de acero inoxidable plegada con bastido 50.50.3. Cierre exterior circular en chapa de acero inoxidable acabado 'americano' de $3 \mathrm{~mm}$.esp. y forrado interior de chapa de acero inox. plegada de $2 \mathrm{~mm}$ esp. s/detalle acabado 'americano'.

85. Pieza de remate de chapa de acero galvanizada y plegada de $2 \mathrm{~mm}$ esp.

rios de contrachapado de tablero marino de $13 \mathrm{~mm}$ esp. con Plegada de $2 \mathrm{~mm}$ esp. acabado 'americano'. Fijación de pilares metálicos $s /$ planos

87.

88. Perfil laminado HEB 340 para arrostramiento de estructura. 


\section{REFERENCIAS BIBLIOGRÁFICAS ADICIONALES}

\section{SOBRE EL EDIFICIO}

(1) 10 x 10/3, 100 Architects, 10 Critics. "Spanish Pavilion, EXPO Zaragoza, Spain 2005-2008". Londres 2009, pp. 212-215.

(2) Arquitectura COAM, 350, Madrid 2007, pp. 86-89.

(3) AV Monografías 133 (2008), pp. 30-41.

(4) "Bosque de acero y barro", Europ'A acero arquitectura. Edita Apta. Número especial, Julio 2008, pp. 32-33.

(5) "Bosque en el agua", Arquitectura Viva 117, Madrid Junio 2008, pp. 56-64.

(6) "El Pabellón de España: La arquitectura del bosque". Catálogo Oficial del Pabellón de España, EXPO Zaragoza 2008. Editorial Metáfora. Junio 2008, pp. 31-43.

(7) "El Pabellón de España gana el VII Premio Cerámica de Arquitectura". Vía Construcción nº 64. Edita Grupo Vía. Barcelona enero 2009, p. 22.

(8) "El Pabellón de Mangado en la Expo, entre los mejores de 2008". Diario de Navarra. Pamplona, 16 enero 2009, p. 52.

(9) FRANCISCO MANGADO 2+2 arquitecto, Editorial Caledoscopio, Lisboa (Portugal), diciembre 2007, pp. 166-194.

(10) FUTURE Arquitecturas, no 4/2006. "Zaragoza 2008". Madrid, septiembre 2006, pp. 48-51.

(11) Kaye Geipel, "Kraftvolle Illusion", Bauwelt 27. Edita Bauverlag BV Gmbh. Julio 2008, pp. 22-25.

(12) Maribel del Álamo, "El Pabellón de España, un ejemplo sostenible", Ambienta, n 77, Ed. Secr. General Téc. del Mº de Medio Ambiente y Medio Rural y Marino. Mayo 2008, pp. 6-13.

(13) Marina Cescon. "Expo Saragozza 2008: Padiglione Spagnolo". Acciaio Arte Architettura n ${ }^{\circ}$ 35, edita Auge Editore srl., settembre 2008, pp. 28-39.

(14) Memoria del Pabellón de España Zaragoza 2008. Edita Sociedad Estatal para Exposiciones Internacionales. Madrid 2008.

(15) "Pabellón de España", Arquitectura Z, no 9-10, ed: La Moderna S.L., Zaragoza. Junio 2008, pp. 62-65

(16) "Pabellón de España, Expo Zaragoza 2008" Revista Arketypo n 12. Edita Excesos Culturales S.L. Agosto 2008, pp. 60-69.

(17) "Pabellón de España. Recinto de la Expo 2008. Zaragoza". Revista On Diseño, no 294. Edita On Diseño S.L, pp. 132-155.

(18) "Pabellón de España". Revista Pasajes Arquitectura n 99, sep. 2008. Edita América Ibérica, pp. 43, 56-73.

(19) "Pabellón de España". Arquitectura EXPO Zaragoza, Proyecto Urbano. Edita Sociedad Estatal Expoagua 2008, S.A. y Actar. Octubre 2008, pp. 77 a 83 y 158 a 167

(20) "Pabellón de España". Infodomus $n^{\circ}$ 22. Edita Infomanews Iberia S.A. Madrid, septiembre 2008, pp. 25-36.

(21) "Pabellón de España, Bosque de Sombras". Revista Diseñart Magazine n 30, Septiembre 2008. Edita Nuevas Fórmulas de Comunicación S.A, pp. 72-83.

(22) "Pabellón de España: un bosque de cerámica sostenible". A/C Arte y Cemento n 16, pp. 80-82.

Padglione della Spagna, BSI SWISS ARCHITECTURAL AWARD 2008. Edita Nicola Navone, Mendrisio Academy Press. Mendrisio, octubre 2008, pp. 112-115.

(23) Pabellón de España en la EXPO 2008 de Zaragoza. Estructuras para Edificios Singulares Españoles. Edita Miguel Aguiló, ACS. Diciembre 2008, pp. 268-271.

(24) “Pavilhão de Espanha, Expo Saragoça 2008. Arqa 65, Arquitectura e Arte. Lisboa, enero 2009, pp. 40-48.

(25) "Premios CONSTRUMAT 2009 a la Innovación Tecnológica por el Pabellón de España en la Expo Zaragoza 2008". El País, 23 abril 2009, p. 19.

(26) Público Privado Efímero, La cerámica en Arquitectura, ASCER, Unión Europea, año 2008, pp 144-149.

(27) Sarah Williams Goldhagen, "The Year in Architecture". The New Republic. 6 enero 2009.

(28) "Spanish Pavillion". Architecture Today no 191. Editada en Londres por Architecture Today PLC, pp. 22-25.

(29) "Spanish Pavilion". Revista C3 n 289, editada en Corea. Agosto 2008, pp. 50-65.

(30) "Spanischer Pavillon EXPO 08, Saragossa". AIT. Alemania, marzo 2009., pp. 154-155.

(31) "Spanish Pavilion for Expo Zaragoza". AND no 14. Firenze, abril 2009, pp. 136-139.

(32) "Sostenibilitá", Allegato a Domus no 918 (suplemento de la Revista Domus, Terra di Spagna). Milán, octubre 2008, pp. 11-19.

(33) Techniques \& architecture Céramiques prospective ceramic mutation, Pavillon espagnol. Saragosse 2008 (Espagne), no 492, París, octubre-noviembre 2007, pp. 68-71.

(34) VVAA. "Pabellón de España", Editor Arquitectura Viva, 2007. ISBN 978-84-612-4460-7. 


\section{SOBRE CUESTIONES TÉCNICAS RELACIONADAS}

(35) Guía 12-2000 de ASHRAE. "Minimizando el Riesgo de Legionellosis Asociado a las Instalaciones de Agua del Edificio". Documento traducido para ATECYR con autorización de ASHRAE por Iñaki Morcillo.

(36) "District Heating \& Cooling de Expo Zaragoza". El Instalador, 450 marzo 2008, pp. 30 y ss.

(37) Neila Gonzalez, Javier. "Arquitectura bioclimática en un entorno sostenible". Editorial Munilla-Leira.

(38) VVAA. "Documentos técnicos de instalaciones en la edificación. DTIE 9.01. Sistemas de climatización", ATECYR, 2001.

(39) VVAA. "Las energías renovables en España. Diagnóstico y perspectivas". Fund. Gas Natural, 2007.

\section{Ficha Técnica}

Proyecto: Pabellón de España para la Exposición Internacional Zaragoza 2008 Situación: Zaragoza

Superficie de actuación: $8.000 \mathrm{~m}^{2}$

Volumen: $28.000 \mathrm{~m}^{3}$

Presupuesto: $18.502 .000 €$

Concurso: 1 er premio concurso ideas

Año de proyecto: 2005-2006

Construcción: noviembre 2006, junio 2008

Cliente e institución de contacto: SEEI (Sociedad Estatal para Exposiciones Internacionales).

Arquitecto: Francisco José Mangado Beloqui.

Colaboradores: Ingeniería de estructuras: Jesús Jiménez Cañas, Alberto López. NB 35.

Instalaciones y estudios de eficiencia energética: Fundación CENER-CIEMAT, Iturralde y Sagüés Ingenieros, César Martín Gómez.

Proyecto: José $\mathrm{M}^{a}$ Gastaldo, Richard Královic, Cristina Chu, Hugo Mónica,

Obra: Cristina Chu, César Martín Gómez.

Arquitecto técnico: Fernando Oliván, Vicente de Lucas.

Constructora: Constructora San José. Jefes de obra: Carlos Riveiro, Antonio Igna-

cio Framiñan, Pedro López Clement, Carlos Paz. 